\title{
Diplomacia financiera en la periferia global: entre la cooperación y la coerción. Aproximaciones teórico-empíricas a partir de las relaciones crediticias de Argentina con Venezuela y China
}

José Marcelino Fernández Alonso*

Artículo recibido: 1 de octubre de 2017

Artículo aprobado: 15 de abril de 2018

Doi: http://dx.doi.org/10.12804/revistas.urosario.edu.co/desafios/a.6139

Para citar este artículo: Fernández Alonso, J. M. (2018). Diplomacia financiera en la periferia global: entre la cooperación y la coerción. Aproximaciones teórico-empíricas a partir de las relaciones crediticias de Argentina con Venezuela y China. Desafíos, 30(2), 43-88. Doi: http://dx.doi.org/10.12804/revistas.urosario.edu.co/desafios/a.6139 Doi: http:// dx.doi.org/10.12804/revistas.urosario.edu.co/desafios/a.6139

\section{Resumen}

El objetivo del presente articulo es analizar las características reportadas por la diplomacia financiera entre los países de la periferia global durante los primeros años del siglo XXI. En términos especificos, el artículo enfoca su escrutinio en los lažos

\footnotetext{
* Investigador asistente del Consejo Nacional de Investigaciones Científicas y Técnicas (CONICET). Docente de Economía Internacional y Finanzas Internacionales, Facultad de Ciencia Política y Relaciones Internacionales, UNR y de Política Exterior Argentina, Pontificia Universidad Católica Argentina (UCA), sede Paraná. Correo electrónico: josefernandezalonso@hotmail.com.
} 
crediticios entretejidos por la República Argentina con la República Bolivariana de Venezuela y la República Popular China (RPC) en aras de sortear su marginación financiera internacional. A modo de hipótesis, el articulo sostiene que los canales y los dispositivos de diplomacia financiera articulados entre Argentina y Venezuela, y Argentina y la RPC resultaron habilitados tanto por la acumulación de reservas internacionales como por la afinidad politico-identitaria, aunque condicionados por el grado de asimetrías entre las partes. Tras la validación empírica de la misma, el trabajo concluye que, aunque relevantes para la concreción de las operaciones crediticias, los factores habilitantes de la diplomacia financiera tuvieron una ponderación desigual: la afinidad político-identitaria (instancia ideacional) gravitó detrás de la disponibilidad de recursos (instancia material). Por otra parte, las modalidades que asumieron dichos canales y dispositivos estuvieron, en efecto, condicionadas por el grado de asimetría entre los Estados intervinientes. De este modo, los desequilibrios estructurales crecientes entre Argentina y la RPC redundaron en que las iniciativas de cooperación financiera se reconocieran ante todo signadas por una lógica coercitiva, en contraste con lo reportado con las vinculaciones con Venezuela.

Palabras clave: diplomacia financiera, periferia global, República Argentina, República Bolivariana de Venezuela, República Popular China.

\title{
Financial Diplomacy in the Global Periphery: Between Cooperation and Coercion. Theoretical-Empirical Approaches Based on the Credit Relationships of Argentina with Venezuela and China
}

\begin{abstract}
This article aims to analyze the characteristics of financial diplomacy in the global periphery during the early years of the $21^{\text {st. }}$ century. Specifically, the paper focuses on the credit operations conducted Argentina with the Bolivarian Republic of Venezuela and the People's Republic of China (PRC) in order to overcome its international financial marginalization. As a bypothesis, the article argues that the channels and mechanisms built under the financial diplomacy ties between Argentina, Venezuela and the PRC were enabled both by the accumulation of international reserves and by a political-identity affinity, although conditioned by their asymmetries. The results
\end{abstract}


of the empirical analysis conclude that despite its relevance for the realization of transactions, the enabling factors of financial diplomacy had an unequal importance: the political-identity affinity (ideational instance) lacked behind the availability of resources (material instance). On the other hand, the patterns assumed by the channels and devices of financial diplomacy were effectively conditioned by the degree of asymmetry between the states. In this respect, the growing structural disparities between Argentina and the PRC led to financial cooperative initiatives mostly characterized by a coercive logic, in contrast to what was observed regarding the links with Venezuela. Keywords: financial diplomacy, global periphery, Argentine Republic, Bolivarian Republic of Venezuela, People's Republic of China.

\section{Diplomacia financeira na periferia global: entre a cooperação e a coerção. Aproximações teórico-empíricas a partir das relações creditícias da Argentina com a Venezuela e a China}

\section{Resumo}

O objetivo do presente artigo é analisar as características reportadas pela diplomacia financeira entre os paises da periferia global durante os primeiros anos do século XXI. Em termos específicos, o artigo enfoca seu escrutinio nos laços crediticios entretecidos pela República Argentina com a República Bolivariana da Venezuela e a República Popular da China (RPC) em favor de sortear sua marginação financeira internacional. A modo de hipótese, o artigo sustenta que os canais e dispositivos de diplomacia financeira articulados entre a Argentina com a Venezuela e a RPC resultaram habilitadas tanto pela acumulação de reservas internacionais como pela afinidade político-identitária, ainda que condicionados pelo grau de assimetrias entre as partes. Após a validação empírica da mesma, o trabalho conclui que, ainda que relevantes para a concreção das operações crediticias, os fatores habilitantes da diplomacia financeira tiveram uma ponderação desigual: a afinidade politico-identitária (instância ideacional) gravitou por trás da disponibilidade de recursos (instância material). Por outra parte, as modalidades que assumiram ditos canais e dispositivos estiveram efetivamente condicionadas pelo grau de assimetria entre os Estados intervenientes. Deste modo, os desequilíbrios estruturais crescentes entre a Argentina 
e a RPC redundaram em que as iniciativas de cooperação financeira se reconbeceram maiormente assinadas por uma lógica coercitiva, $m$ contraste do reportado com as vinculações com a Venezuela.

Palavras chave: diplomacia financeira, periferia global, República Argentina, República Bolivariana de Venezuela, República Popular da China

\section{Introducción}

La gravitación creciente de un contingente de países identificados, históricamente, en la periferia global, supuso una de las manifestaciones más explícitas de los cambios en las estructuras y dinámicas de la arena internacional, producidos en concurrencia con la llegada del siglo $\mathrm{XXI}^{1}$. Tal protagonismo incremental de Estados otrora marginales - y/o marginados, conforme las lecturas teóricas críticas- del sistema internacional tuvo a aquellos convergentes bajo el acrónimo BRICS — Brasil, Rusia, India, China y Sudáfrica - como sus principales exponentes, aunque de forma no excluyente ${ }^{2}$. Hubo diversos

1 Las referencias al término de periferia, en el presente artículo, remiten a los escritos seminales de Raúl Prebisch. Conforme las bases teóricas del consagrado economista, la difusión desigual del progreso técnico y de sus frutos concitó — concita — a que el sistema económico internacional se estructure en términos dicotómicos de centro-periferia (Prebisch, 1987). La periferia está constituida por países/economías que comparten tres rasgos fundamentales, a saber: la heterogeneidad estructural, la especialización productiva y el desarrollo desigual (Rodríguez, 2001). En lo que respecta a la primera característica, Prebisch parte de la premisa de que, en los países periféricos, coexisten sectores y/o ramas con productividad relativamente semejante a la de los países del centro, con aquellos otros rezagados tecnológicamente y con productividad, por lógica, menor. Estos últimos suelen ser los predominantes en la estructura económica de la periferia. En materia de especialización productiva, los países de la periferia se incorporan a los circuitos productivos y comerciales internacionales con productos primarios y/o manufacturas con escaso valor tecnológico incorporado. Tal situación de desigualdad frente al centro se perpetúa, por cierto, dada la tendencia al deterioro de los términos de intercambios. Por último, e intrínsecamente vinculado a lo anterior, los países de la periferia reproducen notables asimetrías sociales en su interior.

$2 \mathrm{Al}$ respecto, hay que mencionar que, junto a los acrónimos BRIC/BRICS, proliferaron otros durante los últimos lustros que tendieron a marcar precisamente el ascenso de países históricamente concebidos como periféricos: NIC (New Industrialized Countries, para dar cuenta del crecimiento de Corea, Taiwán, Hong Kong y Singapur desde la década de los setenta, también denominados "tigres asiáticos"); IBSA (India, Brasil y Sudáfrica); TICKS (Taiwán, India, China, Corea y Sudáfrica); MINST (México, Indonesia, Nigeria y Turquía); entre otros. Análisis específicos sobre estos acrónimos —empleados acríticamente en la mayoría de los casos, cual "modas académicas" - y sobre el papel de las potencias emergentes en la 
indicadores que dieron cuenta de la ponderación más significativa de este grupo de actores en las diferentes dimensiones de la realidad internacional, sobre todo en las económicas. En términos generales, la literatura académica sobre el particular centró su atención en el peso incremental de estos Estados en términos de producción y comercio internacionales, $\mathrm{y}$ no le dio tanta importancia a las referencias a la participación creciente de los mismos en otras áreas clave de la economía mundial, tales como la financiera y la monetaria (Orgaz et al., 2011).

En paralelo a estos cambios de corte sistémico, América Latina —-Sudamérica, en particular- inauguró un nuevo ciclo político-económico tras el malogro del modelo de desarrollo neoliberal y el advenimiento consiguiente de líderes, partidos y movimientos sociales detractores de las reformas promercado implementadas durante los años precedentes. Mucho se ha escrito y dicho con respecto a esta nueva etapa cuya categorización suscitó debates entre los estudiosos de "lo social"”. Sin ánimo de adentrarse en tales discusiones académicas - y políticas, por extensión-, se manifiesta, de modo general, que esta nueva etapa estuvo orientada por una rearticulación Estado-mercado distinta a la consignada durante el apogeo del denominado Consenso de Washington.

La amplitud e intensidad que asumieron estos procesos en la República Argentina la posicionaron a menudo como uno de los ejemplos más acabados. Luego de haber sido expuesto como el "mejor alumno" y el "modelo a seguir" en materia de políticas de liberalización y desregulación por los principales funcionarios de los gobiernos desarrollados y los organismos multilaterales de crédito, el país incurrió, a principios del siglo XXI, en un colapso político-económico sin precedentes en su historia. En efecto, declarada la cesación de pagos de deuda soberana — la

economía global, pueden encontrarse en Joordan (2003), Giaccaglia (2012), Beeson y Higott (2013), Subacchi (2013).

3 "Giro a la izquierda" (Tombón, 2006; Rojas Aravena, 2006; Castañeda, 2006; Plot y Semán, 2007), "post-neoliberalismo" (Borón, 2003; Hiedrich y Tussie, 2009; Stefanoni, 2012) o el advenimiento de gobiernos "progresistas" (Chávez, 2007), "de centroizquierda" (Paramio, 2006), de "nueva izquierda" (Kaufman, 2007; Panizza, 2009), y la siempre polémica categoría de "populistas"/ "neopopulistas" (Laclau, 2006), fueron solo algunos de los calificativos forjados desde la academia para dar cuenta del remozado escenario de la región y sus nuevos gobiernos. 
de mayor dimensión y complejidad a escala global hasta aquel entonces- y producida la salida del régimen cambiario de la convertibilidad ${ }^{4}$, la República Argentina experimentó un deterioro agónico de todos sus indicadores económicos y sociales.

En el plano externo, el estallido de la crisis relegó al país a la situación propia de un "paria internacional" (Loyola Campos, 2004). Este estado de marginación se puso de manifiesto en múltiples áreas o aspectos, ante todo en la negativa de las fuentes tradicionales de financiamiento a conceder nuevos créditos. En este contexto, los actores que intervienen en los mercados voluntarios de deuda resolvieron restringir su exposición financiera a la espera de la resolución del colapso y, sobre todo, de las controversias político-legales interpuestas por inversores extranjeros en foros judiciales y arbitrales internacionales tras el anuncio del default soberano. Lo mismo sucedió con los organismos multilaterales de crédito —el Fondo Monetario Internacional (FMI), principalmente-, preocupados por deslindar su responsabilidad en el auspicio de aquellas políticas identificadas como las causales del descalabro (Neñima, 2011).

Frente a este panorama restrictivo, las administraciones que asumieron tras la debacle - referentes de la nueva etapa regional y críticas, por tanto, de las políticas implementadas durante el ensayo neoliberal- debieron diseñar e instrumentar lineamientos discursivos y de acción con el fin de propiciar la reinserción financiera internacional del país (Fernández Alonso, 2006). Entretanto, recurrieron a canales y a instrumentos de financiamiento alternativos a los utilizados tradicionalmente por el país: por una parte, a recursos domésticos agenciados al compás del proceso de recuperación económica; por otra, a operaciones crediticias ad hoc provistas por potencias históricamente identificadas dentro de la periferia o el Sur Global, particularmente la República Bolivariana de Venezuela y la República

\footnotetext{
4 Implementado por la Ley 23928 en marzo de 1991, el régimen cambiario sostuvo una caja de conversión con una paridad del peso y el dólar en una unidad, lo que permitió superar el proceso hiperinflacionario de aquellos años. En función de ello, fue identificada como el baluarte del modelo económico en el país desde su implementación.
} 
Popular China (RPC). A la postre, estas fueron las principales fuentes de financiamiento externo del país durante la persistencia del estado de default y de la restricción del crédito internacional. Estas maniobras, conviene apuntar, hicieron explícita la articulación de una diplomacia financiera novedosa al conjugar "acciones y/o discursos específicos de política económica exterior orientados a captar recursos e instrumentos financieros de fuentes crediticias no tradicionales" (Fabani y Fernández Alonso, 2017, p. 3). No obstante, aunque permitieron subsanar parcialmente las deficiencias del país en materia de inserción financiera, estas iniciativas instaron a nuevos desafíos e interrogantes políticos y académicos.

Llegado este punto, debe advertirse que desde la configuración del orden de Westfalia, los rasgos y dinámicas asumidos por la diplomacia financiera reprodujeron las bases asimétricas del sistema internacional, en particular los de orden económico. Dicho en otras palabras, históricamente, las vinculaciones diplomático-financieras internacionales se erigieron en torno a las divisiones estructurales de cada coyuntura político-económica: ricos y pobres; desarrollados y en (en vías de) desarrollo; centro y periferia; etcétera. De manera más específica, los primeros fueron - salvo casos y coyunturas excepcionales_ los proveedores de financiamiento y, los segundos, sus tomadores de crédito. Sin embargo, las mudanzas mencionadas del sistema internacional a principios de siglo desdibujaron, en cierta medida, aquellas perspectivas dicotómicas al favorecer que ciertos Estados de la periferia acumularan un acervo considerable de reservas internacionales y entretejieran nuevas y mayores dinámicas de financiamiento para con otros pares $^{5}$.

El objetivo del presente artículo es analizar las características reportadas por la diplomacia financiera entre los países de la periferia global durante los primeros decenios del siglo XXI. En términos específicos, centra su atención en los lazos financiero-crediticios entablados

\footnotetext{
5 Entre los estudios que dan cuenta de este proceso de acumulación de reservas internacionales, fruto del boom de los commodities se destacan los de Gallagher y Porzecanski (2009), Cypher (2010) y Vivares (2018).
} 
entre Argentina y Venezuela, y Argentina y China en aras de sortear su marginación financiera internacional. A modo de hipótesis, el trabajo sostiene que los canales y dispositivos de diplomacia financiera articulados entre Argentina y Venezuela, y Argentina y la RPC resultaron habilitados tanto por la acumulación de reservas internacionales como por la afinidad político-identitaria, aunque condicionados por el grado de asimetrías entre los Estados intervinientes.

Estructurada como un estudio de caso "instrumental", la investigación consignada en el artículo parte de la premisa de que el abordaje de las vinculaciones crediticio-financieras entre Argentina y Venezuela, y Argentina y la RPC permite echar luz sobre los principales rasgos de la diplomacia financiera en la periferia global en tiempos presentes. En consideración de los objetivos e hipótesis de trabajo formulados, las labores de investigación se condujeron conforme un diseño multimodal — también denominado "mixto" - al recurrir a técnicas de relevamiento y análisis de datos inherentes tanto al enfoque cualitativo como al cuantitativo (Hernández Sampieri et al., 2006). En función de ello, se revisaron y sistematizaron documentos oficiales, discursos de representantes de gobiernos e informes estadísticos de organismos nacionales e internacionales ${ }^{7}$. En lo que respecta al tratamiento analítico de los datos, se indica que para el desarrollo de la investigación se recurrió a las técnicas de análisis de contenido y de análisis estadístico.

\footnotetext{
6 De acuerdo con Robert Stake (1998) puede identificarse tres tipos de casos de estudio, a saber: el intrínseco, el colectivo y el instrumental. A diferencia del intrínseco (interesado en el valor propio, peculiar del caso en particular) y del colectivo (consideración de múltiples casos coyunturales con el fin de indagar fenómenos, población y condiciones generales), el estudio de caso instrumental tiene un interés secundario: proveer ideas en torno a un problema o refinar una teoría. De acuerdo con los lineamientos de este abordaje, "los casos son oportunidades de estudiar el fenómeno" de interés, no son el "foco de interés en sí mismo" (Gudermann Kröll, 2001, p. 10).

7 Concretamente, se trabajó con documentos publicados por Presidencia de la Nación, la Jefatura de Gabinete de Ministros de la Nación, el Ministerio de Relaciones Exteriores, Comercio Internacional y Culto, el Ministerio de Economía y Finanzas, el Banco Central de la República Argentina y el Instituto Nacional de Estadísticas y Censos (INDEC). En lo que refiere a los documentos y publicaciones de organismos multilaterales de crédito, se mencionan el World Economic Outlook (FMI) y series estadísticas producidas por el Banco Mundial (BM) y el Banco Interamericano de Desarrollo (BID).
} 
Tras esta introducción, el artículo se desarrolla en tres apartados y unas reflexiones finales a modo de conclusión. En el primero de ellos, se presenta una serie de consideraciones a propósito del concepto de diplomacia financiera y de su aplicabilidad en el marco de las relaciones entre Estados de la periferia. En este contexto, y atento a los objetivos e hipótesis del trabajo, se ensaya una triangulación teórica de aportes propuestos desde diferentes enfoques de las Relaciones Internacionales (RI) y de la Economía Política Internacional (EPI) para abordar las vinculaciones entre identidad, cooperación y coerción internacional. En el segundo apartado, se realiza un breve repaso de la crisis argentina de principios de siglo y del estado de aislamiento financiero experimentado tras el anuncio del default. El tercer apartado tiene por objeto escrutar las vinculaciones diplomáticas financieras entre Argentina y Venezuela, y Argentina y la RPC en términos comparativos. En este entramado, se ponderan las características que adoptaron los mecanismos e instrumentos de financiación provistos al país por ambos Estados. Finalmente, se presentan las conclusiones de la investigación.

\section{Diplomacia financiera: aproximaciones teórico-prácticas desde la periferia}

A pesar de que sus referencias empíricas dan cuenta de usos y prácticas de larga data, los esfuerzos de teorización en torno al fenómeno de la diplomacia financiera resultan relativamente recientes en el campo de las RI y de la EPI, en particular. Históricamente, el conjunto de acciones y/o discursos proyectados por los decisores nacionales en vistas a captar y/o suministrar recursos e instrumentos financieros del ámbito internacional fue concebido por los referentes de las mencionadas disciplinas dentro de las categorías generales de "política exterior" o de "política económica exterior", en sus versiones más sofisticadas. Por otra parte, y conforme explica Maaike Okano-Heijmans (2011), si bien el término de diplomacia financiera encuentra alusiones remotas en informes gubernamentales, notas de prensa y artículos académicos, todas estas instancias adolecieron de pretensiones teórico-explicativas. 
De acuerdo con Nicholas Bayne (2008), el concepto de diplomacia financiera remite a un área o dimensión específica de la política económica exterior por medio de la cual los Estados canalizan sus relaciones financieras externas. A semejanza de todo fenómeno de la realidad social —expresado en el ámbito internacional, por caso—, la diplomacia financiera se reconoce irremisiblemente condicionada por las particularidades de cada coyuntura histórica. En función de ello, el autor apunta que, aunque paradójico, la diplomacia financiera se explicita y conoce los progresos más importantes en tiempos de crisis. Esta idea deriva del hecho de que "cuando las cosas funcionan correctamente, prevalecen las tendencias del statu quo"(Bayne, 2008, p. 3$)^{8}$. Así pues, pueden entenderse las razones por las que la primera década del siglo XXI — en particular luego del estallido de la crisis en Estados Unidos en 2007-2008 que se expandió pronto al resto del globo- acarreó múltiples cambios para la diplomacia financiera, tanto en términos de actores como de prácticas.

$\mathrm{Al}$ entender del precitado autor, la diplomacia financiera contemporánea reporta cuatro caracteres generales. En primer término, involucra los intereses y maniobras de una pluralidad de agencias político-burocráticas que interactúan en el interior de todo gobierno. Concretamente, se trata de un proceso en el que participan los máximos referentes o decisores del Ejecutivo (llámense presidente, primer ministro, etc.), los ministerios de Economía y/o Finanzas y los de Relaciones Exteriores, los bancos centrales, los cuerpos legislativos nacionales, entre otros. Según Bayne, la diplomacia financiera no se clausura en el ámbito gubernamental, sino que articula vinculaciones con actores no estatales, tales como firmas privadas y grupos de interés, tanto nacionales como transnacionales. Por otra parte, el autor sostiene que la diplomacia financiera, llevada adelante en los tiempos presentes, procura asumirse transparente con el fin de agenciar mayor comprensión y legitimidad social. Finalmente, apunta que la diplomacia financiera de hogaño se vale de las instituciones internacionales

8 Traducción propia. 
con el objeto de concretar intereses de orden doméstico, como así también de orden sistémico.

Sin desacreditar las proposiciones de Bayne sobre el particular, se entiende que los rasgos generales recién reseñados deben asumirse cual tipos ideales al no corresponderse a cabalidad con la realidad, mucho menos con la que se expermineta en los países de la periferia global. En consonancia con Maaike Okano-Heijmans (2011), se resalta que las formas y dinámicas de la diplomacia financiera no resultan omnímodas ni universales, sino que tributan a realidades espacio-temporales específicas.

Conforme las premisas de partida del presente trabajo, la diplomacia financiera en (y entre) los países del Sur Global asume ciertas especificaciones que incitan a matizar los razonamientos de Bayne. Para empezar, es de subrayar que, si bien la diplomacia financiera conjuga el interactuar de una pluralidad de agentes y dependencias políticoburocráticas, en el caso de los países de la periferia el universo de los mismos tiende a ser más acotado en relación con lo planteado por el autor. En efecto, al considerársela una cuestión cara a la soberanía y autonomía nacional _elementos constitutivos de la construcción político-identitaria de los países periféricos_-, la diplomacia financiera tiende a estar limitada a aquellos actores que se posicionan en la cúspide o último eslabón del proceso decisorio. De este modo, se indica que, independientemente de los discursos en contrario, la diplomacia financiera en los países de la periferia se caracteriza por articular un proceso circunscripto a las últimas unidades decisionales de los gobiernos y, cuanto mucho, de los bancos centrales ${ }^{9}$. Los

\footnotetext{
$9 \quad \mathrm{Al}$ respecto, si bien es cierto que un número significativo de países periféricos ajustó sus legislaciones durante el predominio del paradigma neoliberal con el fin de "independizar" a los bancos centrales de las presiones coyunturales de los gobiernos de turno, en la práctica dichas normativas suelen ser infringidas y/o atenuadas en las praxis políticas. Frente a coyunturas críticas o de necesidades específicas, los responsables del Poder Ejecutivo tienden a valerse de intersticios legales para imponer su discrecionalidad, relegando, en todo caso, a los responsables de los bancos centrales la operacionalización de lo acordado políticamente. En resumen, es una suerte de consagración de una división del trabajo entre lo "político" y lo "técnico". Existe un número considerable de estudios con respecto al modo en que los bancos centrales
} 
órganos legislativos suelen desempeñar un papel marginal pues tienden a ser convocados de forma tangencial con el fin de cumplir con disposiciones constitucionales sobre el particular, tal cual el caso de la República Argentina ${ }^{10}$. Así las cosas, las referencias a la apertura hacia actores no gubernamentales y de mayor transparencia resultan, cuanto menos, voluntariosas.

Finalmente, en tanto se identifican como promotores de políticas ortodoxas de ajuste, los gobiernos de los países periféricos - los latinoamericanos tras la eclosión del relato neoliberal, en especial- rehusaron históricamente la eventualidad de asumir compromisos con los organismos multilaterales de créditos tradicionales, a menos que las coyunturas críticas se lo impusieran. Más aún, durante los últimos años, apostaron por la institucionalización de organismos y mecanismos de financiamiento bi y multilaterales alternativos a los instaurados bajo el denominado orden de Bretton Woods ${ }^{11}$.

Conforme explica Ana-Cosmina Amariei (2014), la complejidad de ciertas problemáticas en la arena global contemporánea hace que los límites de la diplomacia financiera se confundan y/o se superpongan con los de otras dimensiones de la política económica exterior. No debe resultar entonces extraño que los discursos y acciones inherentes a la diplomacia financiera entre los países de la periferia aludan recurrentemente a otras cuestiones tanto de índole monetaria, como comercial o de inversiones. Dicho en otras palabras, las gestiones de diplomacia financiera no suelen ser sino el puntapié para el desarrollo de otras transacciones: la compra y/o contratación de determinados

entienden y ejercen tal premisa de independencia. A modo ilustrativo, se mencionan los trabajos de Ferreira de Mendonça (2005), De Moraes (2014) y Blancheton (2016).

10 De acuerdo con el Artículo 75, inciso 4, de la Constitución Nacional de la República Argentina, el Congreso tiene la atribución de "contraer empréstitos sobre el crédito de la Nación". Por otro lado, el inciso 7 del mencionado Artículo le atribuye al Congreso la potestad de "arreglar el pago de la deuda interior y exterior de la Nación". Para un análisis detallado de la legislación del país inherente a la cuestión del endeudamiento soberano se recomienda Bruno (2015).

11 A modo ilustrativo, considérense las iniciativas del Banco del Sur y el Banco de los BRICS que propusieron mecanismos decisorios diferentes a los tradicionales basados en la ponderación de cuotas. 
bienes y/o servicios, la radicación de capital bajo la modalidad de inversión extranjera directa (IED), entre otros. Tal como destaca Gerasimus Tsourapas (2017), el reconocimiento de las prácticas de vinculación de cuestiones en las relaciones diplomáticas entre los países de la periferia global viene a complementar un déficit notable de la literatura académica, enfocada en el fenómeno de entrecruzamiento de dos o más cuestiones entre los países desarrollados o centrales y entre los últimos con países en desarrollo o periféricos.

Sin perjuicio de lo anterior, se indica que la vinculación de cuestiones propia de la diplomacia financiera entre los países de la periferia global tiende a robustecer los lazos de cooperación, aunque al costo de incorporarle nuevos factores de incertidumbre. $\mathrm{Al}$ respecto, cabe marcar que, al asociar la concreción y/o continuidad de determinada iniciativa financiera a la concreción y/o continuidad de operaciones conexas, los canales y mecanismos diplomático-financieros pueden verse frustrados en caso de que se produzca una convergencia en las demás cuestiones. Por otra parte, es importante notar que, en términos generales, la vinculación de cuestiones en la diplomacia financiera entre los países del Sur suele no reportar reticencias o resistencias semejantes a las que se conocen, históricamente, a las vinculaciones de estos actores con los del Norte, ya que la misma tiende a apelar a un argumento político-identitario manifiesto: la pertenencia a un devenir histórico común signado por los desequilibrios estructurales internacionales, el cual llama a intensificar y densificar las relaciones entre "pares".

La ventana de oportunidad que abre esta afinidad político-identitaria entre los países de la periferia remite, en buena parte, a las formulaciones de Alexander Went (1994) a propósito de la construcción de la identidad de los actores en el plano internacional y de la articulación de lazos de cooperación. Al "concebir al otro como extensión del 'yo', en lugar de un anatema” (Wendt, 1994, p. 336), los países de la periferia global se presuponen menos amenazados entre sí y, por tanto, más predispuestos a negociar operaciones que comprometen políticas sensibles para las nociones de independencia y autonomía (económica), tales como la monetaria o fiscal (Phlipot, 2010). 
Conviene subrayar que la instancia cooperativa habilitada por la afinidad político-identitaria no implica desconocer la existencia de factores conflictivos en la articulación de canales y mecanismos de diplomacia financiera entre los países de la periferia. En este contexto, es necesario aclarar que en paralelo a la cooperación —entendida como "el ajuste del comportamiento de los actores de acuerdo a las preferencias reales o previstas de los demás" (Axelrod \& Keohane, 1985, p. 226)—, se despliegan elementos coercitivos, propiciados por las diferencias estructurales entre los Estados. Esto es, en última instancia, un fenómeno erigido y sustentado sobre las bases materiales de la realidad internacional. La vinculación de cuestiones desempeña un papel fundamental en la coerción económica, entendida como todo acto por "el cual un Estado determinado amenaza a otro de interrumpir una transacción económica a menos que este último acepte una demanda específica" (Drezner, 2003, p. 1) ${ }^{12}$.

En este punto, puede advertirse que la triangulación teórica-conceptual conjuga aportes provenientes de enfoques diversos de las RI y de la EPI, en particular del racionalismo y del constructivismo. Aunque polémica para las lecturas ortodoxas que rechazan todo ejercicio de triangulación, la articulación que aquí se propone se sustenta en la idea de complementariedad de ambos enfoques formulada por Viviana García Pinzón (2012) para dar cuenta de fenómenos y procesos de cooperación y coerción internacional en los que convergen aspectos ideacionales y materiales.

\section{La República Argentina como paria financiero internacional}

El 23 de diciembre de 2001, luego de semanas de incertidumbre política, económica y social, el presidente provisional Adolfo Rodríguez Saá dio el anuncio, tan temido como esperado por varios actores tanto nacionales como internacionales-, durante el tránsito del país hacia el colapso político-económico y social: a partir de tal fecha, y

\footnotetext{
12 Traducción propia.
} 
por plazo indefinido, la República Argentina suspendía el pago de su deuda soberana.

Sin ánimo de incurrir en una enumeración anodina de datos, estas líneas se limitan a exponer solo algunas consideraciones que ilustran la dimensión del default argentino de aquellos años. En correspondencia con Mortimore y Stanley (2006), se comienza por comentar que, al momento del anuncio de incumplimiento, la deuda soberana argentina representaba alrededor de la cuarta parte de lo transado por aquel entonces en el mercado de bonos de las economías emergentes. De la misma manera, y siguiendo las formulaciones de los mencionados autores, se observa que el monto de los compromisos alcanzados por la declaración de default implicaba dos veces y media el que alcanzó la Federación Rusa en la crisis de deuda soberana de 1998, la cesación de pagos de deuda soberana más abultada hasta entonces. En números concretos, la suspensión de pagos proclamada en diciembre de 2001 "afectó, en principio, a 61803 millones de dólares en títulos y bonos públicos del país y a otros 8030 millones de dólares de obligaciones varias. El remanente —en lo sustancial, deuda con organismos multilaterales (32 362 millones de dólares) — y los recientemente emitidos préstamos garantizados (42 258 millones de dólares) permaneció en situación regular (performing)" (Damill, Frenkel \& Rapetti, 2005, p. 219) ${ }^{13}$.

Más allá de la magnitud de la deuda argentina en default, otras características valieron para posicionarla como la "madre" de todas las cesaciones de pagos soberanas, tal como la denominaron Nouriel Roubini y Brad Setser (2004, p. 298). En este sentido, se debe resaltar que se trataba de la deuda pública en default con mayor variedad de bonos, de jurisdicciones y de monedas involucrados. Compuesta por 152 instrumentos, la deuda argentina alcanzada por la cesación de pagos estaba nominada en 7 monedas $^{14}$ y bajo jurisdicción de 8

\footnotetext{
13 Estos números, conviene agregar, se verían incrementados en el correr del tiempo hasta alcanzar casi 87000 millones de dólares reconocidos como "deuda elegible" en las ofertas de canje realizadas años más tarde por las autoridades político-económicas nacionales.

14 A continuación, las monedas en las que se encontraban emitidos los instrumentos de deuda en cesación de pagos: peso argentino, peso argentino ajustado por la inflación, dólar estadounidense, euro, yen, libra esterlina y franco suizo.
} 
legislaciones diferentes ${ }^{15}$. La dispersión geográfica de sus instrumentos estaba vinculada, intrínsecamente, a estas circunstancias ${ }^{16}$. Por último, no debe de pasar inadvertida la considerable atomización de los tenedores de títulos argentinos ${ }^{17}$.

Todas estas complejidades, propias de la estructura de la deuda argentina, se agudizaban aún más al considerarse la irresolución del denominado debate por la nueva arquitectura financiera internacional (NAFI). Al respecto, conviene recordar que, tras la sucesión de crisis que afectaron a las economías emergentes durante el último lustro del siglo Xx, un significativo universo de académicos, políticos e instituciones de diverso posicionamiento y gravitación se embarcaron en discusiones en pos de (re)adecuar los principios, normas, reglas y procedimientos de toma de decisión ordenadores del sistema financiero internacional a la realidad global tras las vastas modificaciones operadas desde hacía décadas. No obstante, al momento del colapso argentino, el mentado debate - en particular el capítulo dedicado a la resolución de crisis de deudas soberanas— no se había concluido ${ }^{18}$.

15 De los 152 bonos en default, 98 se habían emitido en jurisdicciones distintas a las de la República Argentina (Estados Unidos, Inglaterra, Japón, Alemania, Italia, España y Suiza) (Soto Fajardo, 2008, p. 14).

16 De acuerdo con las estipulaciones del Ministerio de Economía de la República Argentina, al momento de la primera oferta de canje, realizada en 2003 , la deuda en cuestión estaba distribuida de la siguiente manera: República Argentina (38,4\%); Italia (15,1\%); Suiza (10,3\%); Estados Unidos (9,1\%); Alemania (5,1\%); Japón (3,1\%); Reino Unido (1,1\%); Países Bajos (1\%); Luxemburgo (0,8\%). El porcentaje se completaba con los siguientes datos: deuda no identificada (12,8\%), otros (2,5\%) (Ministerio de Economía y Producción, 2003).

17 En función de lo estimado por el Palacio de Hacienda argentino, el 43,5\% de los bonos en suspensión de pagos se encontraba en poder de tenedores minoristas, la mayoría de ellos residentes argentinos, italianos y japoneses.

18 Las discusiones relativas al tratamiento de las deudas soberanas presentaron dos posiciones diferenciadas: por un lado, las propuestas orientadas a "modificaciones institucionales" — representada por la entonces subdirectora gerente del FMI, Anne Krueger- que impulsaban la instauración de un mecanismo internacional de reestructuración de deudas fundado en el capítulo 11 de la Ley de Quiebras de Estados Unidos; por el otro, las propuestas orientadas a "modificaciones contractuales" — apoyadas por el subsecretario del Tesoro, John Taylor, y un grupo de académicos, entre los que destacaba Allan Meltzerlas cuales proponían la inclusión de determinadas cláusulas en todos los instrumentos de deuda emitidos por un Estado soberano. Las diferencias entre estos dos enfoques eran más que significativas: mientras que el enfoque "institucional" propulsaba un reforzamiento del 
Como consecuencia, el país debió ensayar respuestas a su crisis de deuda soberana sin un encuadre institucional internacional definido.

En este contexto, la posibilidad de recibir financiamiento de los organismos multilaterales de crédito estaba vedada ya que, preocupados por evadir las acusaciones de la (co)responsabilidad del malogro argentino, condicionaron su asistencia a la implementación de medidas con grandes costos políticos, económicos y sociales en un escenario ya conflictivo (Nemiña, 2011). Solo después de que iniciara la paulatina recuperación de los indicadores macroeconómicos y sociales como consecuencia de las externalidades positivas de la salida de la caja de conversión y del aumento concomitante del precio internacional de los commodities, los decisores político-económicos nacionales pudieron dar discursos y realizar maniobras para limitar los condicionantes de aquel escenario estructurado por los condicionamientos de los organismos multilaterales de crédito (López Coppola et al., 2003). En este marco, se agenció el respaldo de los gobiernos de las potencias desarrolladas — de Estados Unidos, principalmente- para descomprimir las negociaciones con los funcionarios políticos y burocráticos del fondo. Si bien no se consiguieron "fondos frescos", se habilitaron reprogramaciones de pagos, lo que quitó presión a las cuentas públicas en recuperación. De este modo, el escenario político-económico nacional pudo reencauzarse de forma paulatina hasta proclamar vía elecciones a un nuevo gobierno.

En sus primeros meses de gestión, la administración de Néstor Carlos Kirchner (2003-2007) prosiguió, en términos generales, con los lineamientos macroeconómicos articulados durante los tiempos de su predecesor. Sin embargo, legitimado por el voto democrático y despojado del carácter provisional de Eduardo Duhalde (20022003), el flamante mandatario pudo diseñar y ejecutar una estrategia de reestructuración de la deuda soberana en default (Miranda, 2003).

papel del FMI, las formulaciones "contractuales" ponderaban la "solución de mercado". En abril de 2003, el Comité Monetario y Financiero Internacional del FMI tomó nota de las críticas al proyecto de Krueger y valoró algunos aportes de los postulados contractuales. Se encontrará un análisis detallado de estas discusiones en Swachrcz (2004), Bismuth (2014) y Haley (2014). 
Aunque la mayor parte de los acreedores internacionales se resistió a esta en su primer momento, los gobiernos de los países desarrollados y los funcionarios del FMI la consideraron radical, lo que llevó a que dicha estrategia fuera ajustada en el correr de los meses hasta reportar una aceptación general del $76,15 \%$ de la deuda en situación irregular ${ }^{19}$. Con tal resultado, la administración Kirchner logró una disminución del stock de la deuda en 67000 millones de dólares, todo lo cual implicó una merma de la deuda del 135,4\% al 72,7 \% en términos del Producto Bruto Interno (PBI) (MECON, 2005). Por otra parte, el canje concretado en los primeros meses de 2005 propició una simplificación de la estructura de la deuda al reducir la cantidad de instrumentos financieros de endeudamiento y una disminución de la exposición al riesgo cambiario al haber nominado buena parte de los nuevos títulos en moneda nacional. Pero lo que se creía un paso decisivo para el regreso a los mercados internacionales de crédito, quedó desprestigiado a poco de terminar la operación del canje. La reestructuración de la deuda, aunque necesaria, no era condición suficiente para la concreción de la reinserción financiera del país (Fernández Alonso, 2010).

\section{Las vinculaciones crediticio-financieras de Argentina con Venezuela y la RPC}

Este apartado tiene por propósito explorar y comparar los mecanismos y dispositivos involucrados en la diplomacia financiera entre Argentina y Venezuela, y Argentina y la RPC al constituirse como las principales fuentes de financiamiento externo durante el estado de desinserción financiera internacional iniciado tras la declaración del default y sostenido más allá del proceso de reestructuración iniciado en 2005. Así, se comienza por analizar de modo general el estado de las vinculaciones entre Argentina y sus contrapartes para avanzar

\footnotetext{
19 Formulada a casi tres años de la declaración del default, la primera propuesta de reestructuración — conocida como "oferta de Dubai" por haber sido expuesta en dicho emiratopreveía una quita nominal del $75 \%$ de los títulos públicos en situación irregular y el no reconocimiento de intereses vencidos desde diciembre de 2001. El rechazo mancomunado a la misma concitó a que la segunda oferta presentada por Buenos Aires, en junio de 2004, redujera el porcentaje de la quita, reconociendo los mencionados intereses y la adición de un cupón vinculado al desempeño económico del país.
} 
luego en la indagación de los canales y mecanismos de financiación provista a Argentina por estos países.

\section{La diplomacia financiera entre Argentina y Venezuela}

Cercenado el acceso a los circuitos tradicionales de crédito, los decisores político-económicos de la República Argentina debieron buscar fuentes alternativas de financiamiento ${ }^{20}$. En lo inmediato, tales necesidades pudieron cubrirse a través del uso de los recursos domésticos acumulados al calor del proceso de recuperación económica y de la profundización del esquema arancelario a los commodities exportados - oleaginosas y petróleo, en lo principal - en un contexto de crecimiento de los precios internacionales. No obstante, habida cuenta de la limitación de estos recursos y ante las urgencias de dinamizar y sostener la expansión económica, las autoridades nacionales se embarcaron en la búsqueda de otros mecanismos y/o dispositivos de financiamiento externos.

En esta coyuntura, se forjó la mecánica de la compra directa de títulos públicos argentinos por parte del gobierno de la República Bolivariana de Venezuela, con la que la administración Kirchner había reconocido afinidad político-identitaria desde el inicio mismo de la gestión. A tales efectos, ha de recordarse que tras el acto de asunción de Kirchner, en mayo de 2003, el mandatario entrante y su par venezolano, Hugo Chávez Frías, mantuvieron un encuentro en el que coincidieron en reparar "[...] los daños perversos que hicieron las políticas neoliberales en ambos países, [en] la necesidad de profundizar la integración

\footnotetext{
20 Sin ánimo ni posibilidades de realizar aquí un análisis de las relaciones del país con los organismos multilaterales de crédito durante estos años, estas líneas se limitan a recordar que, en diciembre de 2005, el gobierno argentino anunció su determinación de cancelar el pasivo con el FMI con el fin de desactivar el escenario de confrontación fomentado por los cuestionamientos y demandas incrementales de los funcionarios del organismo para con Argentina. En relación con el BM y el Banco Interamericano de Desarrollo (BID), se observa que si bien durante estos años el país continuó accediendo a sus créditos, los mismos se vieron frecuentemente resentidos por la "solidaridad" interinstitucional entre estos organismos y la negativa de algunos países desarrollados —Estados Unidos, por ejemplo- a aprobar nuevos servicios hacia el país como mecanismo de presión. Para un abordaje acerca de estos procesos, se recomienda Morales Ruvalcaba (2010), Nemiña (2012) y Miranda (2012).
} 
política latinoamericana para cambiar dicho modelo, y [en] la posibilidad de incrementar el comercio bilateral" (Bravi, 2016).

Dicha convergencia político-identitaria se vio reflejada en un reposicionamiento recíproco del lugar de ambos países en las agendas externas respectivas. En coincidencia con Lorenzini (2012), se sostiene que las relaciones bilaterales entre Argentina y Venezuela se transformaron en áreas prioritarias para cada cual en un tiempo relativamente reducido, ganando densidad y profundidad, lo que permitió caracterizarlas con la alegoría de un allegro. Para ilustrar la sintonía entre ambos gobiernos, Roark y Calvento (2011) señalan que entre 2003 y 2007, es decir en solo cuatro años, se suscribió alrededor del $60 \%$ del total de acuerdos bilaterales negociados desde 1911. Más allá del aumento en el número de instrumentos acordados, otros indicadores dieron cuenta del estrechamiento de vinculaciones entre ambos países. En lo que respecta al comercio bilateral, el mismo reportó un crecimiento exponencial: de computar 156 millones de dólares en 2002, el flujo de comercio entre ambos países pasó a 1445 millones en 2010, todo lo cual representó una tasa de crecimiento de 36,6 \% acumulado anual (MECON, 2011). A diferencia de lo ocurrido con otras economías de la periferia, las transacciones comerciales se signaron por la complementariedad. De acuerdo con los informes oficiales y las producciones académicas de los especialistas en la relación bilateral, el esquema de intercambios se asentaba en exportaciones argentinas de determinados productos de los rubros alimenticios y en maquinarias a cambio de energéticos venezolanos. Tal como puede observarse en el gráfico 1, la balanza comercial entre ambos países fue ampliamente favorable para la República Argentina durante todo el período analizado. Sin embargo, como se verá luego, a estos desequilibrios a escala comercial le hicieron contrapeso las operaciones crediticias originadas por Venezuela. 
Gráfico 1. Balanza comercial de Argentina con Venezuela.

1998-2010

(en millones de dólares)

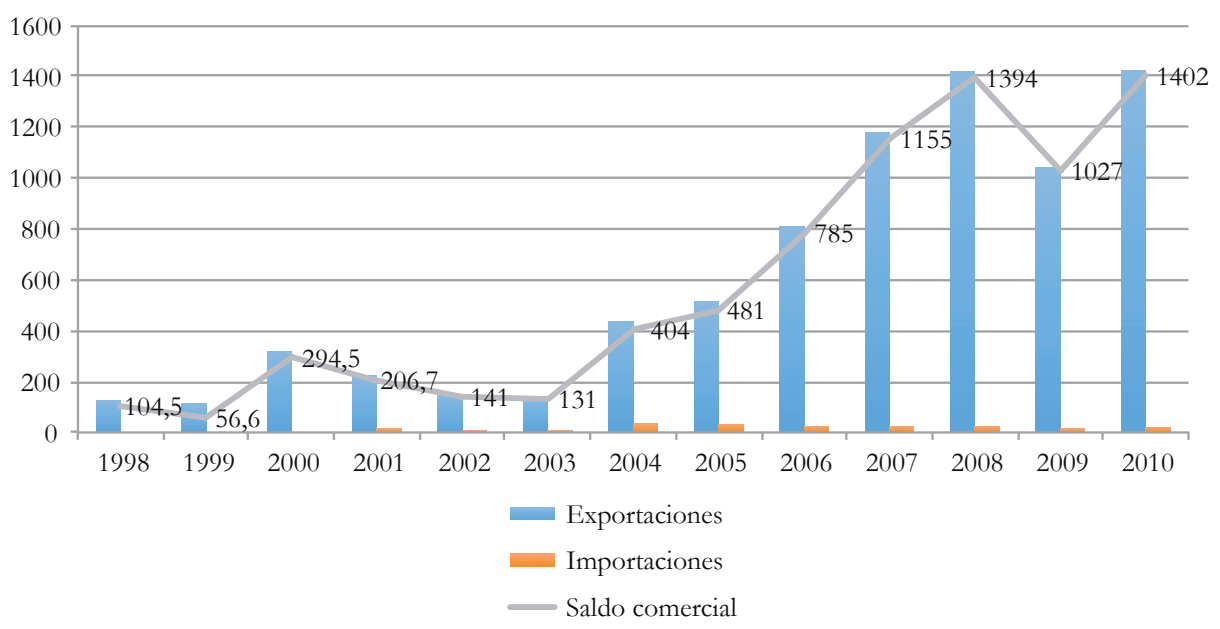

Fuente: Elaboración propia a partir de datos de MECON (2011) y CEI (2017).

A pesar de la contundencia del crecimiento de las transacciones comerciales bilaterales, las operaciones financieras fueron las que adquirieron mayor significación habida cuenta de su carácter inédito. Dicha relevancia del mecanismo de financiamiento provisto por Venezuela quedó evidenciada, no solo al convertirse en la fuente única de recursos externos para el país desde hacía años, sino también por la sumatoria de las operaciones concretadas. Para explicarlo en un gráfico se indica que, entre los años 2005 y 2008, la República Argentina pudo colocar, mediante estas operaciones, instrumentos de deuda pública por una cifra superior a los 9000 millones de dólares, suma total que representó, aproximadamente, la quinta parte de las reservas del Banco Central de la República Argentina (BCRA) al finalizar 2008. Conforme puede observarse en el gráfico 2, al cierre del 31 de diciembre de 2008 las reservas de la institución totalizaban 46386 millones de dólares (BCRA, 2017). 


\section{Gráfico 2. República Argentina. Reservas Internacionales del BCRA. 2001-2017 \\ (en millones de dólares)}

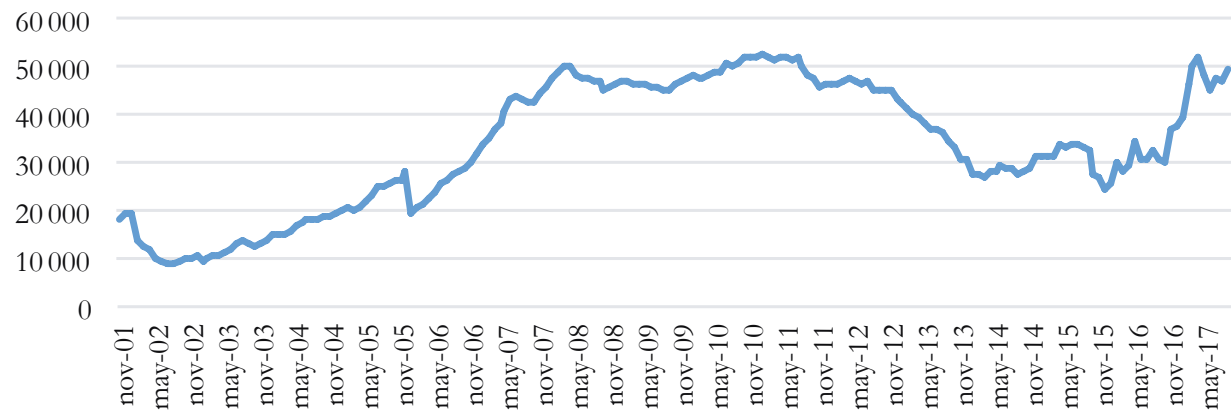

Fuente: Elaboración propia a partir de datos del BCRA (2017) y CEI (2017).

En términos discursivos, la compra directa de bonos argentinos por parte del gobierno de Venezuela se identificó como la manifestación de una nueva etapa en la cooperación regional, que superaba las deficiencias históricas de los países latinoamericanos en su articulación con el sistema financiero internacional. Bajo esta lógica, los Estados de la región debían avanzar en la consolidación de un circuito de financiamiento intrarregional que les permitiera orientar sus recursos excedentes a la atención de las necesidades propias, sin la intermediación de los gobiernos e instituciones de los países desarrollados. En otras palabras, se debía dejar de recurrir a instrumentos financieros de los países desarrollados — funcionales a sus propios interesespara privilegiar, consiguientemente, a aquellos emitidos en la región.

Las operaciones financieras en análisis se canalizaron, ciertamente, bajo el patrón de una "diplomacia presidencial". En este sentido se subraya que, las sucesivas operaciones de compra/venta directa de títulos públicos se concretaron tras negociaciones directas entre los mandatarios de ambos países, y se delegó la instrumentación de las mismas a las agencias técnico-burocráticas encargadas legalmente de ello.

La tabla que se presenta a continuación detalla los alcances de las operaciones por año y título comprendido. 
Tabla 1

Operaciones de venta/compra directa de bonos entre Argentina y Venezuela (2005-2008)

\begin{tabular}{|c|c|c|}
\hline Año & $\begin{array}{c}\text { Monto de la colocación } \\
\text { (en Valor Nominal Original, vNo) }\end{array}$ & Instrumento \\
\hline 2005 & U\$S 1512197700 & BODEN 2012 \\
\hline 2006 & U\$S 2 864 945400 & BODEN 2012 \\
\hline 2007 & U\$S 1987621858 & BODEN 2015 \\
\hline 2008 & U\$S 2 824850310 & BODEN 2015 \\
\hline
\end{tabular}

Fuente: Elaboración propia a partir de datos de Jefatura de Gabinete de Ministros (2009, p. 414).

Dentro del sistema político argentino, el mecanismo de financiamiento provisto por Venezuela suscitó numerosos cuestionamientos. Inscriptos en el debate normativo respecto al estado y devenir de la política exterior argentina contemporánea, los reparos apuntaron, ante todo, a la pertinencia de estrechar vinculaciones con el gobierno de Chávez. Provenientes de referentes políticos, académicos y periodistas detractores del discurso y praxis del presidente venezolano, los cuestionamientos en mención marcaron que el acercamiento a Venezuela operaría en desmedro de las relaciones bilaterales "históricas" de la política exterior nacional: Brasil y Estados Unidos, en concreto. En el marco de estos posicionamientos, fueron recurrentes las alertas sobre una posible dependencia de Argentina a la "diplomacia del petróleo" promovida por el mandatario venezolano en Latinoamérica por aquellos años. En breve, críticas que alertaban sobre los intereses cruzados que podían entretejerse detrás de las relaciones crediticias bajo consideración.

Sin entrar en tal debate respecto a las (in)conveniencias de los ajustes en la política exterior argentina en el largo plazo, hay que advertir que la compra directa de títulos públicos argentinos atendió a necesidades específicas contextuales de ambos Estados. Para la República Argentina, el mecanismo en cuestión validó un canal —inusitadoen su empresa de acceder de nuevo al crédito internacional tras la crisis de deuda soberana de inicios de siglo, y permitió recuperar reservas internacionales tras la reducción cercana a 9000 millones de dólares ocasionada en diciembre de 2005 por la cancelación de la deuda con el FMI. 
El atractivo de las operaciones para Venezuela, mientras tanto, respondió a razones más complejas. Al margen de su aporte al proyecto autonómico de constituir una reserva de instrumentos financieros latinoamericanos y de su alta rentabilidad, los bonos negociados habilitaron un mecanismo adicional para administrar la política de control de cambio vigente en Venezuela desde 2003. En este punto conviene recordar que, en un contexto de cambio controlado, suele producirse una brecha entre un tipo de cambio "oficial" y otro "paralelo", identificada como manifestación o reflejo de otros desequilibrios además de los fundamentales. En el caso venezolano, los bonos argentinos permitieron controlar las variaciones de tal brecha al satisfacer parte de la demanda de dólares del sector privado y reducir, en paralelo, la liquidez de la economía. En relación con esto último, permitieron "esterilizar" el impacto del crecimiento de las reservas internacionales. De acuerdo con Teodoro Petkoff, la dinámica instrumentada operaba de la siguiente manera:

Una vez comprado el bono a la Argentina, el Ministerio de Finanzas venezolano contrata, sin licitación, a bancos internacionales para que diseñen las "notas estructuradas". [...] Luego, el gobierno vende las notas a otros bancos locales venezolanos, también mediante adjudicaciones directas y sin publicar los montos, al tipo de cambio oficial [...]. Para hacerlo, transfiere el papel a una cuenta que el banco comprador debe tener en el exterior, donde no hay restricciones cambiarias. A cambio, el comprador debe pagarle al Ministerio de Finanzas, en Venezuela, los bolívares correspondientes a la compra [...]. El Estado venezolano obtiene así una ganancia cambiaria. ¿Por qué al banco le convino de todos modos la operación? Porque adquirió los bonos al dólar oficial y puede liquidarlos al paralelo. Una vez que el banco venezolano tiene la nota, la aprovecha aquí mediante tres alternativas: 1) la conserva hasta su vencimiento y cobra intereses; 2) la vende al banco internacional emisor, que estructuró la nota, a un valor inferior al que compró, pero al dólar paralelo [...]; 3) la vende a un fondo de pensión o a cualquier comprador externo, también con un descuento, pero al dólar libre (La Nación, 2 de marzo de 2008). 


\section{Gráfico 3. Reservas Internacionales de la República Bolivariana de Venezuela. Septiembre de 2002-septiembre de 2015 (en millones de dólares)}

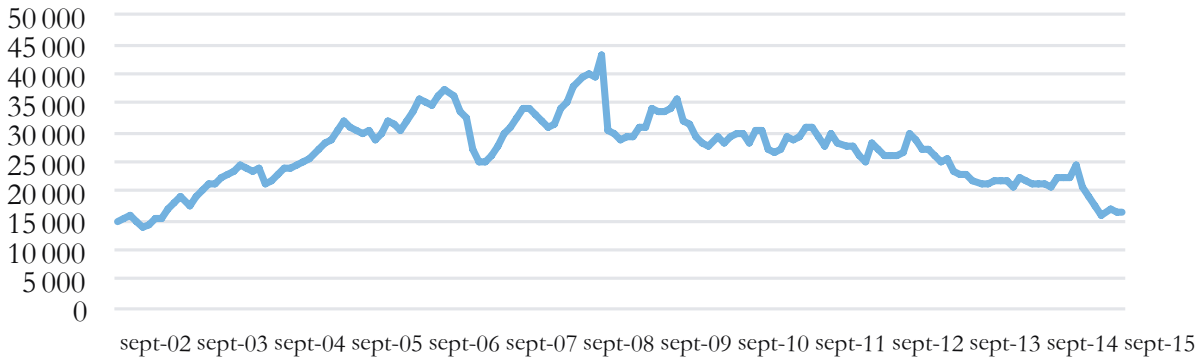
Fuente: Elaboración propia a partir de datos de CEI (2017).

La tasa de interés alcanzada por la colocación directa de deuda soberana a Venezuela fue otro de los aspectos de la mecánica de financiamiento que despertó cuestionamientos. Al replicar las tasas de mercado —elevadas de por sí para un Estado aún sumido en una crisis de deuda soberana-, el costo del endeudamiento mediante la emisión de bonos adjudicados directamente a Venezuela promedió el $14,3 \%$, lo que resultaba muy superior al endeudamiento dispensado por los organismos multilaterales de crédito, el FMI, por ejemplo. En respuesta a estas contrariedades, los decisores político-económicos del gobierno argentino sostenían que el financiamiento bilateral no debía evaluarse exclusivamente por los costos económicos inmediatos, identificados con las tasas de interés, desde luego. Aunque relevantes para la dinámica y el desarrollo de la política de endeudamiento, otras variables debían de sopesarse: el sortear de las condicionalidades de los organismos multilaterales de crédito, el robustecer de mecanismos de cooperación financiera a escala regional, el diversificar el patrón de financiamiento externo, entre otros.

Las derivaciones de la administración de los títulos, por parte del gobierno venezolano, fueron también blanco de críticas. Aunque con argumentos diferentes (y hasta contrapuestos), los cuestionamientos en torno a este aspecto se proyectaron desde ambos países. En el escenario argentino, los miramientos a las repercusiones de las decisiones venezolanas sobre la valorización de los bonos nacionales 
fueron crecientes. Al respecto, cabe indicar que, una vez producida la venta de bonos en el mercado secundario venezolano, se reportaba una caída en la cotización de los papeles públicos argentinos. Cuando el gobierno de Venezuela colocaba los bonos por tramos -mediante la emisión de los denominados "Bonos del Sur"21, por ejemplo-, la baja de los instrumentos argentinos en transacción era menor. El panorama era diferente cuando la colocación al mercado secundario se realizaba en grandes montos. En tales circunstancias, la caída del valor de los bonos argentinos resultaba pronunciada. Tal fue, por caso, la situación que se experimentó a inicios de agosto de 2008, momento en que los bonos argentinos registraron una caída abrupta tras la decisión del gobierno venezolano de desprenderse de 1000 millones de dólares en títulos apenas adquiridos (Ámbito Financiero, 11 de agosto de 2008). En Venezuela, por su parte, las críticas se orientaron al manejo discrecional del gobierno de Chávez de los bonos argentinos. En tal sentido, no faltaron denuncias sobre la escasa transparencia de las relaciones del gobierno con algunas entidades financieras partícipes de la operación.

Las contrariedades expuestas, sumadas al achicamiento de recursos financieros de la República Bolivariana de Venezuela tras la caída del precio del petróleo y el estallido de la crisis internacional en 2007-2008, terminaron por agotar el mecanismo de financiamiento bilateral al promediar 2008. En efecto, erosionadas las bases materiales que habían habilitado y canalizado las iniciativas de la diplomacia financiera a nivel bilateral, la experiencia de cooperación reportó una nueva etapa. Es imperativo remarcar el carácter bilateral ya que ambos gobiernos, signados aún por la afinidad político-identitaria, propiciaron el traslado de los instrumentos de tal diplomacia al plano multilateral; la creación del denominado "Banco del Sur" o los llamados a la conformación de un mecanismo de reestructuración de deuda soberana en la Asamblea de Naciones Unidas son ejemplos claros de ello.

\footnotetext{
21 Los Bonos del Sur fueron instrumentos financieros que combinaron títulos de deuda pública venezolana y argentina. En el período 2006-2007 se realizaron tres emisiones: la primera, en noviembre de 2006, por un monto de 1000 millones de dólares; la segunda, en marzo de 2007, por 1500 millones; la tercera, por último, en septiembre de 2007, por 1000 millones.
} 


\section{La diplomacia financiera entre Argentina y la RPC}

En forma paralela a la erosión de los mecanismos crediticios provistos por el gobierno venezolano, los decisores político-económicos argentinos sondearon otras fuentes alternativas de financiamiento que pudieran sortear las limitaciones derivadas de la persistencia del estado de marginación financiera internacional, más allá del proceso de reestructuración de la deuda iniciado en 2005. En este contexto, comenzaron a sumar intensidad las vinculaciones financiero-crediticias con China, inscriptas también en un patrón de relacionamiento bilateral de mayor amplitud temática y alcance temporal.

Partiendo de la premisa de que el análisis de los canales y mecanismos de diplomacia financiera chino-argentina debe ser antecedido por una contextualización macro de la relación bilateral, hay que comenzar por advertir que, si bien ambos países forjaron relaciones políticoeconómicas incrementales desde la década de los setenta — esto es, desde el restablecimiento de las vinculaciones diplomáticas en 1972-, lo cierto es que los cambios sistémicos operados a inicios de siglo le imprimieron a estas relaciones un salto tanto cualitativo como cuantitativo. Al compás de este proceso de ampliación y densificación, ambos Estados incrementaron sus patrones de vinculación. Aunque en apariencia resulte una verdad de Perogrullo, cabe subrayar que la rejerarquización de la relación bilateral en las respectivas agendas externas no fue idéntica para ambas (Slipak, 2013). Mientras que para la República Argentina las vinculaciones con China se convirtieron en ejes estructurantes para su inserción internacional al referir a un Estado con protagonismo político y económico incremental, para la RPC, Argentina se presentaba como un socio político en los diversos esquemas multilaterales de concertación del Sur y como un proveedor más de recursos naturales y/o con escaso procesamiento industrial.

En aras de evidenciar este reposicionamiento mutuo en las agendas político-económicas mutuas, se marca, a título ilustrativo, que durante el período 1998-2010 la participación de China en las exportaciones argentinas creció del 3 al $8 \%$, incremento que operó a costa de la merma de la relevancia de Brasil y de la Unión Europea (UE) como 
destino de las exportaciones. En lo concerniente al origen de las importaciones de Argentina, vale señalar que China aumentó su participación del 4 al 13\% durante el mismo período (Bravi, 2016). Con todo, y tal como lo expresó Roberto Bouzas (2009), cabe apuntar que los ajustes en el comercio bilateral no resultaran simétricos para ambos Estados. Desde el lado argentino, China ascendió año tras año en importancia en la balanza comercial ${ }^{22}$. Lo opuesto ocurrió, sin embargo, desde la perspectiva china ya que, durante este período, la República Argentina redujo su participación como mercado de destino para las exportaciones chinas (del 0,5 al 0,3\%). Estos datos, huelga apuntar, no hicieron sino refrendar un proceso de crecimiento de las asimetrías entre ambas partes.

\section{Gráfico 4. Balanza comercial de Argentina con la RPC. 2001-2017 \\ (en millones de dólares)}

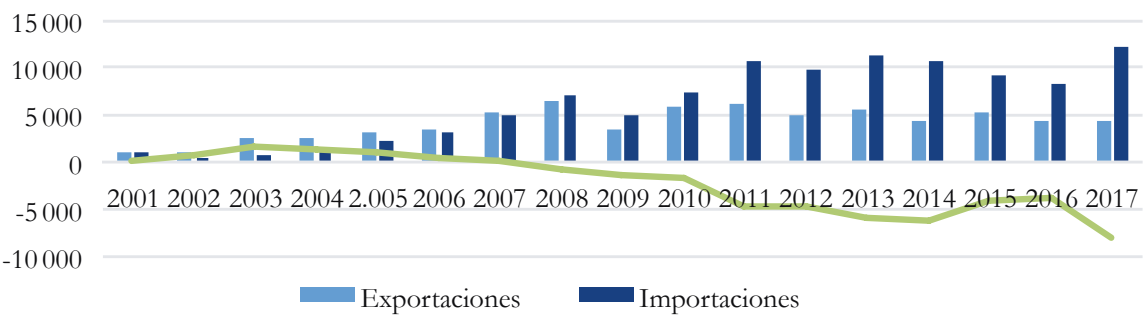

Fuente: Elaboración propia con base en INDEC y DATAINTAL.

Sin dejar de reconocer ciertas deficiencias metodológicas relativas a la medición de las operaciones de IED originadas en la RPC, se observa que la radicación de capital chino al país — aunque increyente- tuvo un ritmo y un monto significativamente menor comparado con los flujos comerciales ${ }^{23}$. El gráfico presentado a continuación da cuenta cabal de ello.

\footnotetext{
22 En 2009 —esto es el momento en el que comenzó a intensificarse la diplomacia financiera entre ambos países_- China se posicionaba como el cuarto mercado de destino de las exportaciones argentinas al tiempo que se consagraba como el tercer proveedor del país.

23 Los expertos en las inversiones chinas en América Latina coinciden en reparar ciertas desviaciones y/o contrariedades en las metodologías de registro de estas operaciones. Al respecto, puede señalarse, en primer término, que algunos países latinoamericanos no desglosan en sus registros operaciones de inversiones por orígenes de las mismas. En segundo término,
} 


\section{Gráfico 5. Stock de inversiones de la RPC en la República Argentina. 2007-2015 \\ (en millones de dólares)}

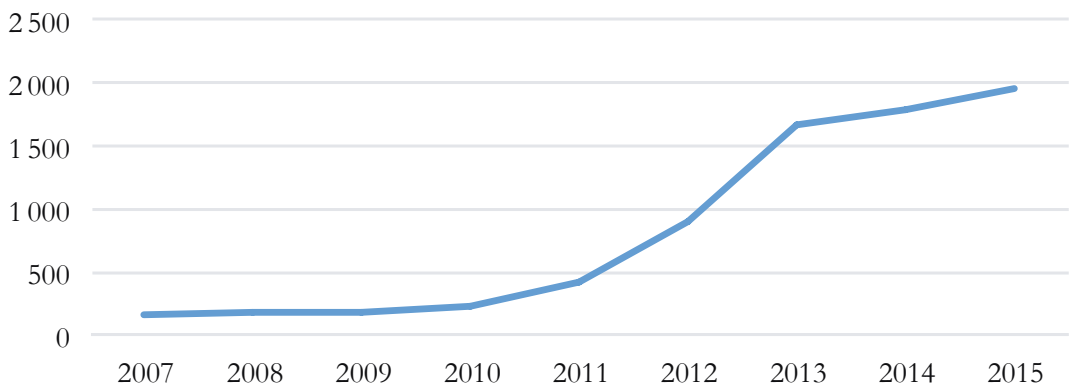

Fuente: Elaboración propia a partir de datos de Ministerio de Comercio de la RPC (2016).

En lo que concierne a los mecanismos y dispositivos de diplomacia financiera, estos también tuvieron un crecimiento exponencial. Conforme la hipótesis de trabajo, este fenómeno particular estuvo habilitado por el incremento de las reservas internacionales de la RPC y la afinidad político-identitaria. En relación con la primera variable, de acuerdo con Cardenal y Araujo (2012), merced a las reformas económicas iniciadas desde fines de la década de los setenta y a la expansión económica sostenida desde entonces, el país comenzó a acumular reservas — primero en forma paulatina, luego, más raudamente-, todo lo cual terminó de posicionar al país como uno de los mayores acreedores mundiales. Al compás de este proceso, sus entidades financieras empezaron a ganar porciones significativas de mercados en marco de procesos de internacionalización. Según explican los autores, las reservas de divisas chinas (que sumaban 2,85 billones de dólares al cierre de 2010), provienen de cuatro flujos: la inversión extranjera directa en la RPC, el superávit comercial, el turismo y el llamado proceso de esterilización de su moneda (compra de divisas para mantener un determinado tipo

se debe destacar que un porcentaje muy importante de la IED proveniente de China queda asentado como proveniente de otros territorios, comúnmente conocidos como "paraísos fiscales", desde donde se tercian las operaciones al país de destino final. Por último, la RPC canalizó su creciente gravitación económica en la región no solo mediante la modalidad tradicional de transacciones de inversión extranjera, sino por la vía de préstamos especiales que suelen garantizar la contratación excluyente de empresas de su nacionalidad (Stanley \& Fernández Alonso, 2016). 
de cambio) (Cardenal \& Araujo 2012, p. 133). Tal como apunta Solimano (2015, p. 14), “[...] todo esto contribuye a que China cuente con enormes recursos financieros, los cuales invierte en proyectos de desarrollo tecnológico y en infraestructura y otorga apoyo financiero a las empresas chinas en el extranjero".

Esta proyección creciente de la RPC como fuente crediticia internacional — para los países en desarrollo, en particular- se inscribe como un capítulo específico de la estrategia going global impulsada por el gobierno chino en los primeros años del siglo XXI. Mediante esta estrategia, el país procuró — procura, al constituirse en un proceso aún presente- articular un nuevo patrón de inserción internacional que le asegure el abastecimiento de recursos requeridos por su modelo de desarrollo (Friedberg, 2006; Gallagher et al., 2012). De modo general, la mayor parte de los préstamos internacionales de China son otorgados por el Banco de Desarrollo de China (BDC) y por el Ex-Im Bank ${ }^{24}$. El resto de los préstamos proviene principalmente del Banco Industrial y Comercial de la China (ICBC) y del Banco Central de China, también conocido como Banco del Pueblo Chino (IISCAL, 2016). Los acuerdos de intercambio de divisa, a los que se referirá luego, son negociados y motorizados precisamente por este último ${ }^{25}$.

Conforme explican Kevin Gallagher, Amos Irwin y Katherine Koleski (2013), los créditos otorgados por China en Latinoamérica durante

\footnotetext{
24 Irene Solimano (2015) explica que el BDC apoya sobre todo las políticas macroeconómicas de China que se enfocan en ocho áreas de desarrollo: energía eléctrica, construcción vial, ferrocarriles, petróleo y petroquímica, carbón, correo y telecomunicaciones, agricultura e industrias relacionadas e infraestructura pública. Por el contrario, el mandato del Banco Ex-Im de China es: "facilitar las exportaciones e importaciones de productos mecánicos y electrónicos chinos, completar un conjunto de equipos y productos nuevos y de alta tecnología, ayudar a las empresas chinas con ventajas comparativas en sus proyectos de contrato en el extranjero e inversiones en el exterior y promover las relaciones de China en el extranjero y la cooperación económica y comercial internacional". La institución cubre este conjunto de objetivos a través de créditos para la exportación y la importación, préstamos para contratos de construcción o proyectos de inversión en el extranjero, préstamos concesionarios del gobierno chino, préstamos interbancarios internacionales, etc. (Gallagher et al., 2013, p. 5).

25 Un análisis detallado del proceso decisorio de los acuerdos económicos internacionales de la RPC puede encontrarse en Vadell et al. (2017).
} 
los últimos lustros superaron la combinación de los empréstitos del BM, el BID y el Ex-Im Bank de Estados Unidos. A diferencia de los préstamos de estas instituciones, el financiamiento chino se destinó principalmente a países con dificultades en el acceso a otras fuentes internacionales de financiamiento, tales como Argentina, Ecuador y Venezuela. Con respecto a Venezuela, se señala que los créditos que se le concedieron equivalen a cerca de la mitad del total de préstamos provistos por China a la región. Por cierto, préstamos concedidos bajo la modalidad de "reembolso en especie", en este caso, mediante la exportación de petróleo. Este es, en resumen, el mencionado mecanismo de vinculación de cuestiones.

Si bien la RPC no exige condicionalidades semejantes a las requeridas por los organismos multilaterales de crédito tradicionales, sus préstamos no escapan a tal lógica coercitiva al incorporar cláusulas político-económicas tanto de jure como de facto. En lo que respecta a las primeras, se advierte que, al igual que lo reportado en todas las iniciativas encuadradas en la macrorelación, las operaciones crediticias se encuentran sujetas al reconocimiento del principio de "una sola China” (Stanley \& Fernández Alonso, 2018). Las condicionalidades de hecho están dadas por la aceptación de demandas en las cuestiones vinculadas.

En el caso específico de Argentina, la diplomacia financiera se orientó mediante dos canales específicos: por una parte, préstamos directos para financiar la compra de productos manufacturados en la RPC; por otra parte, swaps, o intercambios de moneda entre los bancos centrales respectivos lo que, a la postre, implica préstamos indirectos.

Hasta el cierre del presente artículo ${ }^{26}$, la República Argentina y la RPC habían suscripto cuatro préstamos directos. El primero de ellos fue aprobado en 2010 por un monto cercano a los 10000 millones de dólares para comprar equipos y materiales varios para la modernización del sistema ferroviario argentino, particularmente en la región

26 Septiembre de 2017. 
metropolitana de Buenos Aires y en las provincias de Santa Fe y Córdoba. En la práctica, se trató de un mecanismo crediticio por el que los recursos estaban restringidos a la concreción de determinadas compras. El segundo préstamo, por otra parte, se suscribió a mediados de 2014. En concordancia con lo realizado en el anterior, la nueva línea crediticia se forjó para la compra de material ferroviario. Tal como explica Francisco Martirena Auber (2014), "el convenio de crédito comprador" fue suscripto entre el Ministerio de Economía y los bancos BDC y ICBC por el monto de aproximadamente 2100 millones de dólares. Como se había fijado el 11 de marzo de 2010 con el acuerdo contractual para el proyecto de Rehabilitación del Ferrocarril Belgrano Cargas, las obras habrían de estar encabezadas por la sociedad estatal China Machinery Engineering Corporation (CMEC) y por la China Machinery Engineering Argentina Sociedad Anónima (CMEA). En números concretos, el crédito se hizo a una tasa del 7,5\% y a un plazo de quince años. En este contexto, se puede decir que, aunque superior a la provista por los organismos multilaterales de crédito tradicionales, la tasa era menor a la que podía conocerse en los mercados internacionales.

En lo que concierne al segundo mecanismo y/o dispositivo en el que se condujeron las vinculaciones diplomáticas financieras, se menciona que con el propósito de sortear los efectos de la crisis financiera internacional, las autoridades económico-monetarias de la República Argentina gestionaron con éxito durante los primeros meses de 2009 un swap de monedas por un monto de 70000 millones de yuanes, lo que equivalía a 38000 millones de pesos (o 10200 millones de dólares, según la tasa de cambio de aquel entonces). Motorizado por el afán de asegurarse "el acceso a divisas internacionales en caso de una eventual iliquidez", conforme al comunicado de prensa emitido entonces por el BCRA, este mecanismo — cuya extensión se había fijado por el plazo de tres años- no llegó nunca a instrumentarse al no haberse perforado el nivel de reservas establecido como "piso crítico" en el acuerdo. Cabe señalar en este marco que se trataba del primer swap labrado por el Banco Central chino con un país latinoamericano. Hasta entonces, tal institución había sellado acuerdos de este tipo con Corea del Sur, Malasia, Indonesia, Hong Kong y Bielorrusia por un total de 650000 
millones de yuanes (lo que para entonces equivalía a unos 95000 millones de dólares). Estos acuerdos, bien vale resaltar, no solo se explicitaron como concurrentes de la estrategia de internacionalización de la moneda China sino como la determinación de replicar las maniobras ensayadas por la Reserva Federal de Estados Unidos y por el Banco Central Europeo en otras latitudes del globo. El hecho de que Argentina fuese el primer país latinoamericano en suscribir este tipo de acuerdo no se explica solo por el acervo de reservas chinas ni por una estrategia geoeconómica a escala global. En este marco debe señalarse que, en noviembre de 2004, el país había suscripto un "acuerdo de asociación estratégica" con la RPC, ampliando el "acuerdo de asociación” firmado en 2001. Tal como exponen Javier Vadell, Roberto Brandão Araújo y Gustavo Rojas De Cerqueira César (2017), estos acuerdos suponen una lógica de compromiso y entendimiento incremental ${ }^{27}$. Para los objetivos de este trabajo, se entiende que estos acuerdos constituyen evidencia de la afinidad político-identitaria entre los Estados firmantes ya que los mismos remiten a una: "[...] cooperación basada en el respeto mutuo, beneficio mutuo, confianza mutua y el principio del win-win", tal como lo explicara oportunamente el premier Wen Jiabao (Vadell et al., 2017, p. 178).

En términos generales, se puede decir que los circuitos en los que se encarrilaron las iniciativas de diplomacia financiera entre Argentina y China remitieron a negociaciones entre "las primeras y segundas líneas" de los bancos centrales, entre los diversos ministerios del Poder Ejecutivo, ministerios afectados por el problema (de Economía, Finanzas, Relaciones Exteriores) y entre las autoridades de los respectivos bancos centrales. En este sentido, tales iniciativas se canalizaron en procesos más estandarizados, aunque sin relegar el elemento de discrecionalidad política propia de la diplomacia financiera de los países de la periferia global.

\footnotetext{
27 En julio de 2014, la República Argentina suscribió un acuerdo de asociación estratégica integral (Comprehensive Strategic Partnership, CSP), el instrumento de cooperación de mayor relevancia para la diplomacia china.
} 
En julio de 2014, en el marco de una merma de las reservas internacionales del BCRA tras una serie de reveses judiciales en las demandas instauradas contra el país por tenedores de títulos públicos en default ante la justicia estadounidense ${ }^{28}$, las autoridades de la mencionada institución y del Ministerio de Economía negociaron un nuevo swap con sus pares chinos por un monto levemente superior en términos reales a los acordados en el instrumento de 2009. A tales efectos, se menciona que el nuevo acuerdo preveía un eventual intercambio de monedas por un equivalente a 11000 millones de dólares. De acuerdo con la información emitida por el BCRA, se destaca que a diferencia de aquel suscripto en 2009 , en este acuerdo se "habrían mejorado significativamente las condiciones de uso, flexibilizando plazos, reduciendo costos y autorizando usos adicionales a los que previamente habían sido acordados" (Página 12, 7 de septiembre de 2014). Este swap se efectivizó en diversos tramos, los cuales permitieron a la administración argentina, presidida por Cristina Fernández de Kirchner (2007-2015), despejar inquietudes con respecto al agotamiento de las reservas internacionales del país. Pero esto, conviene resaltar, no estuvo despejado de contrariedades. Tal como marcan Patricio Almeida Gentile y Luciano Jara Musuruana, la devaluación de la moneda china del 4,4\% anunciada en los primeros días de agosto de 2015 desnudó la vulnerabilidad del swap como mecanismo de fortalecimiento de reservas. En sus palabras, "Dado que gran parte de las reservas se encuentran originalmente denominadas en yuanes, una devaluación por parte de China afecta la valorización del swapa la baja y, en consecuencia, el nivel informado de reservas internacionales se contrae. De esta forma, la devaluación implicó una disminución de 365 millones de dólares de reservas" (Almeida Gentile \& Jara Musuruana, 2015, s/d).

Si bien en la comunicación oficial sobre las condiciones de estos créditos se cuidaron de no aludir a otras dimensiones de la relación bilateral, no debe escapar que las tratativas de este segundo crédito swap coincidieron con las discusiones en torno a dieciséis acuerdos

\footnotetext{
28 Conforme pude advertirse en el gráfico 2, de computar cerca de 47000 millones de dólares en abril de 2009, las mismas habían pasado a sumar solo 29500 millones en julio de 2014 .
} 
firmados aquellos días junto a la declaración sobre el establecimiento de la "asociación estratégica integral". Tal cual lo observó Ricardo Carciofi (2015), la gran mayoría de estos instrumentos mantuvo su contenido en reserva, lo que suscitó fuertes cuestionamientos por parte de la oposición y de la opinión pública, en general. Más allá de las críticas a su carácter secreto, los acuerdos recibieron otras más al abordar cuestiones sensibles a la soberanía y a la autonomía político-económica. En este marco conviene recordar que, en paralelo al swap, se negociaron un Convenio Marco de Cooperación en Materia Económica y de Inversiones — que preveía la adjudicación directa de proyectos de infraestructura y la posibilidad de contratación de mano de obra de origen chino en las mismas condiciones que el mercado laboral argentino, entre otras cosas-, y un Acuerdo de Observación Espacial en la Provincia de Neuquén, que autorizó la instalación de una base de investigaciones aeroespaciales china en la provincia argentina de Neuquén, agencia dependiente en última instancia de las Fuerzas Armadas de dicho Estado.

Cabe aclarar que los canales y mecanismos de financiamiento provistos por la RPC traspasaron la alternancia de gobierno en Argentina cuando Mauricio Macri, candidato de la alianza electoral de centroderecha Cambiemos, llegó a la primera magistratura del país con la premisa de cambiar el modo de inserción internacional ${ }^{29}$. Si bien durante la campaña electoral Macri había realizado declaraciones respecto a una revisión eventual de los acuerdos estrechados durante la administración precedente con la RPC, enviando incluso una carta al embajador de China en el país, Yang Wanming, a tal efecto ${ }^{30}$, apenas asumió como presidente debió dejar de lado aquellas expresiones de

\footnotetext{
29 Para un abordaje más profundo de las premisas y los lineamientos de la política exterior de la administración Macri se remite a los trabajos de Busso y Zelicovich (2016) y Simonoff (2016). Para la problemática específica de las relaciones con la RPC, se recomienda Hua (2017) y Oviedo (2017).

30 Tal como advierte Eduardo Oviedo (2017, p. 22) a partir de una nota del diario El Cronista, Macri expresó en aquella carta "que este tipo de convenios comprometen al Estado argentino hacia las próximas décadas y requieren amplios consensos, así como una profusa información sobre los compromisos que en ellos se establecen y una clara fundamentación de su conveniencia y alcances. Lamentablemente ello no ha ocurrido".
} 
reserva. Ciertamente el complejo de condicionantes domésticos y externos que signaron su asunción llevó a que el presidente enviara a su primer ministro de Hacienda, Alfonso Prat Gay, y al entonces secretario de Finanzas, Nicolás Caputo, a la RPC a negociar la ampliación del swap negociado en la gestión anterior, maniobras que redundaron en la firma de un acuerdo suplementario del swap, el 16 de diciembre de 2015. Tal gesto buscó sumar reservas internacionales ante la inminencia del acuerdo con los tenedores de títulos públicos en situación irregular y mostrar solidez de la nueva gestión.

Fruto de este acuerdo, el gobierno pudo convertir 20000 millones de yuanes que estaban depositados en una cuenta a nombre del BCRA, en dólares. Del mismo modo, la persistencia de las necesidades de financiamiento marcó que, en julio de 2017, las autoridades políticomonetarias nacionales solicitaran una extensión por tres años más del mentado swap. Las condiciones que enmarcaron la continuidad de este acuerdo evidenciaron el rasgo coercitivo subyacente en la diplomacia financiera chino-argentina. En este sentido, se sostiene que tras advertir que la revisión de un acuerdo en un área específica conllevaría a la revisión de toda la agenda de cooperación bilateral (los canales y dispositivos de diplomacia financiera, desde luego, entre ellos), la administración Macri debió dar marcha atrás con aquellas expresiones que tendían a renegociar acuerdos firmados por la gestión anterior. En todo caso, y siguiendo el análisis de Eduardo Oviedo (2017), la administración Macri buscó reducir la creciente dependencia financiera con la RPC tras la vuelta del país a los mercados. De este modo se explica el hecho de que el país continuara accediendo al financiamiento pese al distanciamiento político-ideológico abierto tras la asunción del nuevo gobierno.

\section{Reflexiones finales}

Las modificaciones suscitadas en las estructuras y dinámicas del sistema internacional redundaron en la aparición de nuevos patrones de vinculación entre los Estados de la periferia, siendo los canales y dispositivos de la diplomacia financiera una manifestación cabal de 
ello. A este respecto, cabe apuntar que el ascenso de un colectivo de "emergentes" y el incremento consiguiente del precio de los commodities habilitaron recursos para auspiciar e instrumentar discursos y acciones de diplomacia financiera en - y entre - los países de la periferia global.

Aunque en apariencia resulte paradójico, las condiciones sistémicas que licenciaron la propagación de los discursos y las acciones de la diplomacia financiera periférica devinieron — devienen - en sus principales flancos y desafíos. En este marco, se resalta que los dispositivos de la diplomacia financiera entre los países periféricos resultan altamente dependientes de los recursos de los Estados. Al respecto, considérese el caso de la compra de títulos públicos argentinos por parte de Venezuela, iniciativa remozada que se vio resentida frente a la ralentización, primero, y caída, luego, del precio del petróleo. Lo propio se puede señalar en relación con los mecanismos de financiamiento provistos por la RPC, que también se vieron menguados en los últimos años como consecuencia de la merma en sus tasas de crecimiento y la acentuación de diagnósticos más cautelosos con respecto a su desempeño futuro inmediato y a largo plazo.

Términos semejantes se pueden plantear en relación con la dimensión político-identitaria, otro de los factores habilitantes de la diplomacia financiera entre los países de la periferia global. Tal como se observó en cuanto a las vinculaciones entre Argentina y Venezuela, y Argentina y la RPC, la afinidad político-identitaria —expresada en las ideas y/o creencias compartidas de un derrotero común en oposición a otro (el "centro", por caso) — alentó la instrumentación de cada una de las iniciativas. A tales efectos, cabe mencionar que la negociación e implementación de los diversos mecanismos de financiamiento abordados estuvo recurrentemente acompañada y/o fue institucionalizada por discursos e instrumentos ponderadores de trayectorias y desafíos comunes. Sin perjuicio de lo anterior, es importante notar que el peso de esta variable resulta menor al reportado por el elemento material. Conforme pudo apreciarse en el marco de las relaciones diplomáticas financieras argentino-venezolanas, la erosión de las reservas internacionales de la última tras la caída del precio 
del petróleo inhabilitó la continuidad de las iniciativas encaradas, al menos en el plano bilateral. Por su parte, en lo que respecta a las relaciones con la RPC, se constató que los canales y dispositivos de financiamiento continuaron sosteniéndose más allá de la alternancia de gobierno, esto es, más allá de un desvanecimiento de la afinidad político-identitaria. Sin embargo, los resultados de esto último no descartan la relevancia del elemento ideacional. En este sentido, es de gran importancia subrayar que se continuaron con las iniciativas previas, mas no se generaron otras nuevas.

Conforme se advirtió en la hipótesis de trabajo, los elementos que habilitaron las iniciativas de diplomacia financiera entre los países de la periferia global resultaron acompasados por la existencia de factores que las constriñen. En este contexto, hay que hacer referencias al grado de (a)simetría entre las partes. Tal como se advirtió en el análisis de las vinculaciones financiero-crediticias de Argentina con Venezuela y la RPC, los dispositivos y mecanismos de financiamiento se condujeron de modo diferenciado. Mientras que en el caso de las iniciativas con Venezuela hubo un patrón de financiamiento sin condicionalidades político-económicas, en el caso de RPC, los dispositivos e instrumentos negociados e implementados reportaron efectivamente la existencia de tales restricciones. Más aún, las asimetrías estructurales entre las partes -explicitadas en la gravitación del comercio e inversiones bilaterales, por ejemplo- forzaron el entrecruzamiento de cuestiones más ostensibles, lo que lleva a pensar la diplomacia financiera con la RPC bajo una lógica en la que el elemento coercitivo estuvo más presente. Esto último, bien vale remarcar, no implica desconocer cierta coerción en las iniciativas con Venezuela ya que, como bien se explicó, los instrumentos que canalizaron la diplomacia financiera argentino-venezolana replicaron tasas de interés de mercados, altas de por sí, para un Estado soberano con problemas de deuda soberana.

En vista a lo anterior, puede colegirse que los mecanismos y dispositivos de diplomacia financiera en la periferia global devinieron - devienen - en una fuente de oportunidades para afianzar lazos estratégicos entre actores que se perciben parte de un colectivo y para propiciar el desarrollo conjunto. No obstante, se repara en la 
conveniencia de no idealizarlos ni analizarlos bajo lecturas ingenuas y/o voluntaristas ya que, a semejanza de lo que ocurre en el sistema internacional en su todo, en los mismos convergen elementos propios de cooperación y coerción.

\section{Referencias}

Almeida Gentile, P. \& Jara Musuruana, L. (2015). Radiografía del swap Argentina-China. Observatorio Económico Social UnR. Recuperado el 5 de septiembre de 2017 de http://www.observatorio.unr.edu.ar/ radiografia-del-swap-argentina-china/

Amariei, A. C. (2014). Economic diplomacy in the context of economic crisis. Europolity, 8(1), recuperado el 4 de mayo de 2017 de http:/ / europolity.eu/wp-content/uploads/2014/12/Vol.8.No_.1.2014_7-31.pdf

Axelrod, R. \& Keohane, R. (1985). Achieving cooperation under anarchy: Strategies and institutions. World Politics, 38(1), 226-254.

Blancheton, B. (2016). Central bank independence in a historical perspective. Myth, lessons and a new model. Economic Modelling, (52), 101-107.

Bayne, N. (2008). Financial diplomacy and the credit crunch: The rise of central banks. Journal of International Affairs, 62(1), 1-16.

Beeson, M. \& Higgott, R. (2013). The changing architecture of politics the Asia-Pacific: Another (lost) middle power moment? The role of middle power in $21^{\text {st }}$ century International Relations, 2013. Recuperado el 14 de abril de 2017 de https: / www.kf.or.kr/front/archv/downloadFile.ht ml?filetype $=$ D\&filename $=201401108741959392774382 . p d f$

Bismuth, R. (2014). The path towards an international public policy for sovereign debt contracts. Brazilian Yearbook of International Law.

Bouzas, R. (2009). China y Argentina: relaciones económicas bilaterales e interacciones globales. en: Autores Varios, China-Latinoamérica: una visión sobre el nuevo papel de China en la región (pp. 283-301). México: Instituto de Investigaciones Jurídicas, UNAM.

Borón, A. (2003). El posneoliberalismo: un proyecto en construcción. En E. Sader \& P. Gentili (Eds.), La trama del neoliberalismo (pp. 141-150). Buenos Aires: CLACSO. 
Busso, A. \& Zelicovich, J. (2016). El gobierno de Mauricio Macri y la integración regional desde el MERCosur a la Alianza del Pacífico. Conjuntura Austral, 7(37), 17-24.

García Pinzón, V. (2012). Entre la cooperación y la coerción: las relaciones de Estados Unidos con Colombia y México en torno a las drogas ilícitas. En J. A. Zavaleta Betancourt (Coord.), La inseguridady la seguridad ciudadana en América Latina (pp. 347-392). Ciudad Autónoma de Buenos Aires: ClACSO.

Bravi, B. (2016). Soft power de Argentina. La politica exterior del gobierno de Néstor Kirchner. Tesis de Maestría en Relaciones Internacionales (mimeo). La Plata: Instituto de Relaciones Internacionales (IRI)-Universidad Nacional de La Plata (UNLP).

Bruno, E. (2015). The legislation of Argentina on its sovereign debt (mimeo). Recuperado el 4 de septiembre de 2017 de https://ssrn.com/ abstract $=2657219$

Carciofi, R. (2015). Argentina-China. Una asociación estratégica integral. Alquimias Económicas. Recuperado el 14 de diciembre de 2017 de https://alquimiaseconomicas.com/2015/03/25/argentina-chinauna-asociacion-estrategica-integral/\#_ftn5

Cardenal, J. P. \& Araujo, H. (2012). La silenciosa conquista china. Barcelona: Editorial Crítica.

Castañeda, J. (2006). Latin America's left turn. Foreign Affairs, 85(3). Recuperado el 16 de julio de 2017 de https://www.foreignaffairs.com/ articles/south-america/2006-05-01/latin-americas-left-turn

Chávez, D. (2007). Hacer o no hacer: los gobiernos progresistas de Argentina, Brasil y Uruguay frente a las privatizaciones. Nueva Sociedad, (207). Recuperado el 14 de abril de 2017 de http:// nuso.org/articulo/ los-gobiernos-progresistas-de-argentina-brasil-y-uruguay-frente-alas-privatizaciones/

Cypher, J. M. (2010). South America's commodities boom: Developmental opportunity or path dependent reversion? Canadian Journal of Development Studies/Revue canadienne d'études du développement, 30(3-4), 635-662.

De Moraes, T. (2014). Banco Central de Brasil: ¿Público o privado? Reflexiones sobre la ambivalencia del Banco Central de Brasil y sobre el amparo legal de la emisión de moneda. Revista de Sociales y Jurídicas, (10), 24-45. 
Damill, M., Frenkel, R. \& Rapetti, M. (2005). La deuda argentina: historia, defaulty reestructuración. Desarrollo Económico-Revista de Ciencias Sociales, 45(178), 187-233.

Drezner, D. (2003). The hidden hand of economic coercion. International Organization, 57(3), 643-659.

Fabani, O. \& Fernández Alonso, J. (2017). Diplomacia financiera con fuentes crediticias no tradicionales durante la gestión de Mauricio Macri. Los casos de China, Qatar y Emiratos Árabes Unidos (2015-2017). Ponencia preparada para el XIII Congreso Nacional de Ciencia Política, Sociedad Argentina de Análisis Político (SAAP), Buenos Aires, 2 al 5 de agosto de 2017.

Fernández Alonso, J. (2006). La reinserción financiera como eje rector de la agenda externa argentina post-default. En B. A. Bologna, La politica exterior argentina (2003-2005) (pp. 31-88). Rosario: Centro de Estudios de Relaciones Internacionales (CERIR), UNR Editora.

Fernández Alonso, J. (2010). La cuestión de la reinserción financiera en la política económica exterior de la República Argentina tras el proceso de reestructuración de la deuda (2005-2009). En B. A. Bologna, La politica exterior argentina en el gobierno de Cristina Fernández de Kirchner (pp. 51-98). Rosario: Centro de Estudios de Relaciones Internacionales (CERIR), UNR Editora.

Ferreira de Mendonça, H. (2005). La independencia de los bancos centrales y su relación con la inflación. Revista de la CEPAL, (87), 171-189.

Friedberg, A. L. (2006). "Going out": China's pursuit of natural resources and implications for the PRC's grand strategy. Washington: National Bureau of Asian Research.

Gallagher, K., Irwin, A. \& Koleski, K. (2012). New banks in town: Chinese finance in Latin America. Report. Inter-American Dialogue. Recuperado el 22 octubre de 2017 de http://ase.tufs.edu/gdae/Pubs/rp/ GallagherChineseFinanceLatinAmerica.pdf

Gallagher, K., Irwin, A. \& Koleski, K. (2013) ¿Un mejor trato? Análisis comparativo de los préstamos chinos en América Latina. Cuadernos de Trabajo del Cechimex, (1), 1-42.

Gallagher, K. P. \& Porzecanski, R. (2009). China and the Latin American commodities boom: A critical assessment. PERI Working Papers, (164), $1-27$. 
Giaccaglia, C. (2012). Estrategias de quodlibet en el escenario internacional contemporáneo. Las acciones de IBSA —-India, Brasil y Sudáfricaen los ámbitos multilaterales. Revista Brasileira de Política Internacional, 56, 90-108.

Gundermann Kröll, H. (2001). El método de los estudios de caso. En M. L. Tarrés (Coord.), Observar, escuchar y comprender. Sobre la tradición cualitativa en la investigación social (pp. 231-264). México, D. F.: Colegio de México-FLACSO.

Haley, J. (2014). A Sovereign Debt Restructuring: Old Debates, New Challenges. CIGI Papers, (32), 1-21.

Hernández Sampieri, R.; Fernández-Collado, C. \& Baptista Lucio, P. (2006). Metodología de la investigación. México: McGraw Hill/Interamericana Editores.

Hiedrich, P. \& Tussie, D. (2009). Post-neoliberalism and the new left in the Americas: The pathways of economic and trade policies. En L. McDonald \& A. Ruckert (Eds.), Post-neoliberalism in the Americas (pp. 37-53). Londres: Palgrave.

Hua, L. (2017). Las relaciones económicas y comerciales entre China y Argentina en la era de Mauricio Macri. Relaciones Internacionales, 26(53). Jordaan, E. (2003). The concept of a middle power in international relations: Distinguishing between emerging and traditional middle powers. Politikon, 30(2), 165-181.

Laclau, E. (2006). La deriva populista y la centroizquierda latinoamericana. Nueva Sociedad, (205). Recuperado el 16 de junio de 2017 de http:// nuso.org/articulo/la-deriva-populista-y-la-centroizquierda-latinoamericana/

Lorenzini, M. (2012). La relación Argentina-Venezuela 2003-2010: ¿Un vínculo de tiempos oscilantes? Trabajo presentado en las jornadas de debate: "La agenda de la política exterior argentina: inserción regional y extra-regional a partir del escenario post-default'. Facultad de Ciencia Política y Relaciones Internacionales. Universidad Nacional de Rosario.

Kaufman, R. (2007). Political Economy and the "new left". En C. J. Arnson \& J. R. Perales (Eds.), The "new left" and democratic governance in Latin America (pp. 24-30). Washington: Woodrow Wilson International Center for Scholars. Disponible en: https://www.wilsoncenter.org/ sites/default/files/NewLeftDemocraticGovernance.pdf [Última consulta: 16/04/2016]. 
López Coppola, C., Tosi, S. \& Verdi, M. C. (2003). La relación ArgentinaFMI: el uso de los costos recíprocos. Revista de Relaciones Internacionales, 12(24), 1-20.

Loyola Campos, A. (2004). De la crisis, la pobreza y otros demonios: la economía argentina. Comercio Exterior, 54(10), 918-924.

Martirena Auber, F. (2014). Argentina habilitó crédito chino de US\$2 100 para trenes y espera acuerdo sobre represas. BAE, sección Economía y Finanzas, martes 15 de julio de 2014. Recuperado el 2 de agosto de 2017 de http:/ / www.diariobae.com/notas/24496-argentina-habilitocredito-chino-de-us2-100-m-para-trenes-y-espera-acuerdo-sobrerepresas.html

Miranda, R. (2003). Política exterior argentina. Idas y venidas entre 1999-2003. Rosario: Ediciones PIA.

Miranda, R. (2012). Bush-Obama y la continuidad de la sanción política a Argentina. Intellector, (16), 1-17.

Morales Ruvalcaba, D. (2010). La política exterior de Néstor Kirchner y el diseño de un regional core state sudamericano. Contextualizaciones Latinoamericanas, (3), 1-44.

Mortimore, M. \& Stanley, L. (2006). Obsolescencia de la protección a los inversores extranjeros después de la crisis argentina. Revista de la CEPAL, (88), 17-34.

Nemiña, P. (2011). Estrategias de negociación del FMI y la Argentina durante el período 2003- 2004. Temas y Debates, (22), 87-113.

Nemiña, P. (2012). Argentina: camino del desendeudamiento (1991-2011). Ola Financiera, (12), 70-88.

Okano-Heijmans, M. (2011). Conceptualizing economic diplomacy: The crossroads of International Relations, Economics, IPE and Diplomatic Studies. Hague Journal of Diplomacy, (6), 1-2.

Orgaz, L., Molina, L. \& Carrasco, C. (2011). El creciente peso de las economías emergentes en la economía y gobernanza mundiales. Los países BRIC. Documentos Ocasionales, (1101), 5-52.

Oviedo, E. (2017). Alternancia política y capitales chinos en Argentina. En E. Oviedo (Comp.), Inversiones de China, Corea y Japón en Argentina. Análisis general y estudio de casos (pp. 12-35). Rosario: UNR Editora.

Panizza, F. (2009). Nuevas izquiedas y democracia en América Latina. Revista CIDOB d'Afers Internacionals, (85-86), 75-88. 
Paramio, L. (2006). Giro a la izquierda y regreso del populismo. Nueva Sociedad, (205). Recuperado el 16 de agosto de 2017 de http: / / nuso.org/ articulo/giro-a-la-izquierda-y-regreso-del-populismo/

Phlipot, C. (2010). Economic diplomacy: Views of a practitioner. En Strategic Studies Institute of the US Army War College (SSI). Carlisle: US Army War College. Recuperado el 7 de julio de 2017 de http:/ / www.isn.ethz.ch/ Digital- Library/Publications/Detail/?id=119503

Plot, M. \& Semán, E. (2007). Neither/nor: Mapping Latin America’s response to neoliberalism and neoconservatism. Constellations, 14(3), 355-372.

Prebisch, R. (1987). Cinco etapas de mi pensamiento sobre el desarrollo. Comercio Exterior, 37(5), 1077-1096.

Roark, M. \& Calvento, M. (2011). Condicionantes internos y externos de las relaciones de Argentina con Venezuela. La transformación del vínculo bilateral durante el gobierno de Néstor Kirchner. En S. Colombo. La inserción internacional de Argentina durante la presidencia de Néstor Kirchner: un cambio de época. Tandil: CIEPIL-UNCPBA.

Rodríguez, O. (2001). Raúl Prebisch. La actualidad de sus ideas básicas. Revista de la CEPAL, (75), 41-52.

Roubini, N. \& Setser, B. (2004). Bailouts or bail-ins, responding to financial crises in emerging economies. Washington: Institute for International Economics.

Rojas Aravena, F. (2006). El nuevo mapa político latinoamericano. Nueva Sociedad, (205). Recuperado el 2 de agosto de 2017 de http://nuso. org/articulo/el-nuevo-mapa-politico-latinoamericano/

Simonoff, A. (2016). Giros en las estrategias de inserción argentina a partir de la presidencia de Mauricio Macri. Conjuntura Austral, 7(37), 40-51. Slipak, A. (2013). Las relaciones entre la República Popular China y la Argentina bajo los postulados del modelo de crecimiento con inclusión social. Revista Voces en el Fénix, 4(26), 96-103.

Stake, R. (1998). Case studies. En N. Denzin \& Y. Lincoln (Eds.), Strategies of qualitative inquiry (pp. 443-466). London, New Delhi: Sage.

Stanley, L. \& Fernández Alonso, J. (2016). El tratamiento a las inversiones extranjeras tras el ascenso de la República Popular China: ¿De las reglas a la discreción? Cuadernos del CECHIMEX, (3), 1-23.

Stanley, L. \& Fernández Alonso, J. (2018). The changing problem of regional development financing in Latin America. En E. Vivares, Regionalism, development and post-commodities boom in South America: Analyses about the unequal South (pp. 101-120). London: Palgrave Macmillan. 
Stefanoni, P. (2012). El posneoliberalismo cuesta arriba. Nueva Sociedad, (239). Recuperado el 14 de julio de 2017 de http:/ / nuso.org/articulo/ posneoliberalismo-cuesta-arriba-los-modelos-de-venezuela-bolivia-yecuador-en-debate/

Solimano, I. (2015). Emergencia de China como principal socio comercial de los países de América del Sur y su impacto en las estructuras productivas de la región (2002-2014). Consideraciones a partir de los casos de Argentina, Brasil y Venezuela (mimeo). Tesina de grado. Facultad de Ciencia Política y Relaciones Internacionales, Universidad Nacional de Rosario.

Subacchi, P. (2008). Power and rules in the changing economic order. International Affairs, 84(3), 485-498.

Schwarcz, S. (2004). "Idiot's guide" to sovereign debt restructuring. Emory Law Journal, (53), 1189-1218.

Tobón, M. J. (2006). El giro latinoamericano: del malestar neoliberal a gobiernos reivindicados de izquierda. Perspectivas Internacionales, (2), 33-37.

Tsourapas, G. (2017). Migration diplomacy in the Global South: Cooperation, coercion and issue linkage in Gaddafi's Libya. Third World Quarterly, 38(10), 1367-1385.

Vadell, J., Aráujo, R. \& de Cerqueira César, G. (2017). China y la nueva ofensiva financiera en América Latina: los acuerdos con Argentina. En G. Lechini \& C. Giaccaglia (Eds.), Poderes emergentes y cooperación Sur-Sur. Perspectivas desde el Sur Global (175-192). Rosario: UNR Editora.

Vivares, E. (Ed.). (2018). Regionalism, development and the post-commodities boom in South America. London: Palgrave Macmillan.

Wendt, A. (1994). Collective identity formation and the international state. American Political Science Review, 88(2), 384-396.

\section{Documentos oficiales}

Banco Central de la República Argentina (BCRA). (2017). Reservas internacionales y principales pasivos del Banco Central de la República Argentina. Al 30 de junio y al 31 de diciembre de 2008-2016. Buenos Aires. Iniciativa para las Inversiones Sustentables China-América Latina (IISCAL). (2016). Los préstamos de los bancos chinos en 2015. Boletín Especial No. 3. Washington, D. C.: Bank Information Center. 
Jefatura de Gabinete de Ministros (JGM). (2009). Informe del Jefe de Gabinete de Ministros Doctor Aníbal Domingo Fernández a la Honorable Cámara de Diputados de la Nación. Informe No. 76, Buenos Aires, noviembre. Recuperado el 2 de agosto de 2017 de http:/ /www.jgm.gov.ar

INTAL. (2017). Estadísticas comerciales detalladas. Recuperado el 5 de noviembre de 2017 de http:/ / dataintal.intradebid.org

Ministerio de Economía y Producción (MECON). (2005). Oferta de canjeAnuncio final. 18 de marzo de 2005, Buenos Aires.

Ministerio de Economía y Producción (MECON). (2011) El comercio exterior bilateral entre Argentina y Venezuela. Documento de trabajo (mimeo). Recuperado el 13 de agosto de 2017 de http://www.economia.gob. ar/peconomica/dnper/documentos/Venezuela_Jun2011.pdf

Ministerio de Comercio de la República Popular China. Buró Nacional de Estadísticas y Administración Nacional de Divisas Extranjeras. (2017). Boletin estadístico de inversiones extranjeras directas de China. Beijing: China Statistics Press. 